\title{
Exploring the Effects of Financial and Fiscal \\ Vulnerabilities on G7 economies: \\ Evidence from SVAR Analysis
}

\begin{abstract}
We examine the possible interactions of the financial cycle and fiscal position for G7 economies. We employ the innovative aggregate financial and fiscal stress indexes which are able to depict the perplexed nature of modern economies. A SVAR model is developed to investigate the effects of both financial and fiscal stress on key macroeconomic variables. The results, using two different identification methods, reveal that financial and fiscal shocks affect negatively the key macroeconomic variables. Additionally, there is a weak feedback effect from a financial shock to fiscal sector and vice versa.
\end{abstract}

JEL Classification: E44, F47, G01

Keywords: Financial Stress, Fiscal Stress, Structural VAR, G7 Economies 


\section{Introduction}

The aim of this paper is the investigation of the financial cycle and its potential interconnections and interdependencies with the fiscal position for G7 economies. The current financial and sovereign crisis, previous episodes of abrupt growth as well as financial stalls indicate that the sole investigation of the reasons affecting financial conditions and business cycles is not enough so as to evaluate and assess the several crises episodes emerged in the global economy. One of the major accusations for the economic profession during the latest crises is the inability of the modelling frameworks used to indicate the forthcoming financial meltdown and the ensuing fiscal burden for the troubled economies. There are a few studies examining the financial cycles and their properties, like Claessens et al. (2011), while others try to investigate the relation of business and financial cycles (see, Claessens et al. 2012 and Tagkalakis 2013).

In our work, we move one step further by incorporating in our modelling approach a number of aggregate indices, able to capture the financial conditions and the fiscal position of the economies under investigation. These are the so called financial and fiscal stress indices (hereafter FSI and FiscSI, respectively). Their major advantage is the broad coverage of stand-alone indicators, representing different sources of instability that can lead to episodes of financial upheaval and fiscal strain into one single variable. In this way, a much richer set of information is implemented, so that a more accurate depiction of the main threats of an economy's stability can be provided. Additionally, the aforementioned indices are good representatives of the conditions prevailing in the financial cycles (FSI) and the fiscal stance of the scrutinized countries (FiscSI).

A well-established causal relationship between the monetary and financial cycles with the business cycle is provided by Andrian et al. (2010). In that paper, the link of a flatter term spread with gloomier growth prospects, because of the credit expansion seizure, is established. Thus, our indices that represent the economic and 
financial conditions are good tools for the empirical investigation the aforementioned relationships. Furthermore, the importance of such tools is stressed by Kastrop et al. (2012), where the authors discuss the efforts for the creation of a unified early warning indicators framework for the Euro Area countries, after the current crisis outbreak ${ }^{1}$. The scope of this new framework is the production of early signals for potential vulnerabilities on the fiscal, financial and sovereign sides of the economies. A special emphasis is attributed to the kind of institutional framework that allows the prompt application of the necessary macroeconomic policies for the alleviation of crises effects.

We base our analysis into a SVAR model in order to estimate the effects of both financial and fiscal stress on four key macroeconomic variables; real GDP growth, inflation, short-term interest rates and nominal effective exchange rate. Using recursive ordering as well as pure sign restrictions, we explore the macroeconomic effects of unexpected shocks in the financial and fiscal conditions using quarterly data for the G7 economies. To the best of our knowledge this is the first attempt to analyse the interactions of financial and fiscal vulnerabilities through these indexes. To briefly illustrate our results, a shock in financial stress index is not always reflected in deteriorating fiscal conditions. The reverse is also true for a fiscal shock. Additionally, for almost all the examined cases, a sudden financial and fiscal shock affects negatively the output growth, inflation and interest rate. On contrary, the effects on exchange rates are mixed. Overall, it is a major step in the research agenda, towards a deeper understanding of how these crucial factors operate and affect the evolution of the economies around the world.

The remaining paper is organised as follows. Section 2 provides a review of the literature. Section 3 presents the data used along with a discussion about the construction of the indexes and the econometric methodology used. Section 4

\footnotetext{
${ }^{1}$ Policy makers are extremely interested in these indexes, something evident from the intense research effort made by many central banks around the word, especially the Federal Reserve. Consult Hatzius et al. (2010) for more information.
} 
discusses the estimated impulses responses and the historical decompositions. Section 5 provides further evidence and, finally, Section 6 discusses the results.

\section{Literature Background}

One of the most intensely debated issues in economics is the business cycles, their fluctuations and the respective effects on the level of economic growth. Many economists have investigated their behaviour, tipping points as well as the exact timing of the shift from one phase of the cycle to the next one. On the other hand, there is a strand of economic literature growing lately, the purpose of which is the examination of the so-called financial cycles. This kind of research was amplified due to the incidence of the recurring financial crises. Especially, given the current financial and sovereign crisis that hit the developed economies and, most recently, the Euro Area countries, the interest on this topic is inflated again.

One of the first papers providing stylised facts of the financial cycles is Claessens et al. (2011). The authors analyse the financial cycles for 21 advanced economies for the last half century. The innovative feature here is the decomposition of the financial cycle to credit, house and equity prices cycles, according to the type of variables used. According to their analysis, the financial cycles downturns are more intensive, lasting between five and eight quarters, while the upturns are longer and slower. Additionally, the equity and house prices cycles are more pronounced than the credit ones. At a cross sectional level, it holds for the credit and equity cycles. In general, the global synchronization of downturns leads to longer and deeper recessions.

Based on this work, Claessens et al. (2012) proceed to an investigation of the financial and business cycles interactions. Their research covers a period of fifty years again, from 1960 to 2010, with forty four countries included to their sample. An interesting finding is the strong ties between the different phases of the two types of cycles. An association between exacerbated recessions and the house and equity 
prices is established. How smooth is the process of transition from the recession to the recovery phase is directly linked with the financial cycle. In this way, the authors emphasise the role of the financial assets on the real economy. In general, financial cycles are sharper and deeper than the business ones, while both exhibit bigger swings in emerging markets than in the developed economies.

On a similar fashion, Drehmann et al. (2012) provide concurrent evidence with the previously mentioned economists, concerning the house and equity prices fluctuations. They specify the duration of the financial cycles to be about sixteen years, following an increasing tendency since the mid 1980's. In a similar vein, Kannan (2012) study the effects on the economy's recovery phase from a recessionary period, when the latter is the outcome of a financial crisis incidence. His research is based on industry - level data, specializing on firms that heavily rely on external finance for their operations. The empirical work provides evidence that recessions induced by financial upheavals cause higher output losses, by 10 to 15 percent, in industrialized economies. Moreover, the recovery period is more prolonged, compared to the case where a recession is not caused by financial sector abnormalities. The author provides a number of reasons for this phenomenon, namely the nature of the financial crisis, the size of shock to the potential output of the economy or the external environment.

Another part of this literature has tried to empirically assess the aforementioned interconnections. Chen et al. (2012), using a multivariate unobserved component model, study the interest rates, output, asset prices and credit nexus for the US economy. According to their results, these variables' cycles are closely related and concurrent. Moreover, Karfakis (2013) study the relationship of credit and business cycles for Greece, in the last decade. Real GDP represents the business cycle behaviour, while the real credit is made of the aggregate claims on the private sector of the economy. One of the outcomes is that credit is a useful indicator for monitoring future changes in the Greek business cycle. Additionally, credit drying up during the recent crisis is a factor that deepened the recession. 
Tagkalakis (2013) investigate the effects of financial market crises on the fiscal positions of 20 OECD countries, for the period 1990 - 2010. The most important finding is a significant deterioration of fiscal durability during financial crises. Especially for economies with well developed financial markets, these effects are stronger, in terms of lost output. In these cases the fiscal interventions are bigger, while there is a positive relation of financial market crashes with debt levels deterioration.

As it is evident from this literature, our financial stress indices constitute a good representation of the financial cycle. There is a wide coverage of the financial markets, achieved through the inclusion of variables representing the credit, equity and asset prices conditions. In this way, our financial stress indexes are an efficient metric of the financial markets conditions. On the other hand, it is imperative to provide a similar metric, which can represent the conditions prevailing to the fiscal stance of an economy. As it is evident from the current sovereign crisis that has hit hard many Euro Area countries, governments are in need of tools able to provide them with early warnings of future fiscal strains and imbalances. Since, to a great extent, the business cycle behaviour is defined by the countries fiscal conditions, we provide a number of fiscal stress indices in this paper. In the following, we provide a discussion of the relevant literature.

One of the very first papers, indicating the importance of monitoring the evolution of a broad spectrum of fiscal conditions indicators, is the one by Hemming and Petrie (2000). The importance of fiscal sustainability is emphasized, based on theoretical and practical policy considerations providing a number of metrics that can, potentially, provide useful insights in public finances. In terms of the criteria for choosing the vulnerability indicators, they suggest doing it according to the initial fiscal position of an economy, the short-term fiscal risks, the long-term sustainability and the respective structural weaknesses. For the initial fiscal position, they suggest the overall fiscal balance to GDP ratio and net financial debt to GDP. For the case of short-term fiscal risks, the maturity and the currency composition of debt are 
proposed. The changes in primary balance and demographic changes projections are the indicators able to outline the long-term fiscal sustainability. Finally, for the structural fragilities of an economy, the recommended measures are the expenditure indicators (like military expenditure/GDP) and some revenue indicators (revenue composition, tax elasticity, non-tax revenue as a share of total revenue).

Although the Hemming and Petrie's work provides interesting insights and theoretical justifications for the proposed fiscal sustainability indicators, it does not move forward to a methodology for the construction of composite fiscal stress indicators. This is done by Baldacci et al. (2011a), where the authors provide a set of variables as early warning indicators of fiscal strain and rollover risk that can be included in a relevant aggregate index. Their contribution is the development of a fiscal monitoring framework, through the construction of two aggregate indices (namely, a fiscal vulnerability and a fiscal stress index)2.

Using this framework, Baldacci et al. (2011b) have produced fiscal stress indexes for both advanced and emerging economies. Using annual data for the period $1970-2010$, they find that the best predictors of fiscal turmoils for advanced economies are the gross financing needs and the fiscal solvency risks variables. Regarding the emerging economies, the most important factors are the public debt structure and the spillover risks from the international financial markets. Focusing on the current crisis, the authors provide evidence of heightening fiscal stress for both groups of countries, while the leaders of this increase are Europe and North America ${ }^{3}$.

Since the concept of fiscal stress indicators has only recently been developed, the lack of empirical applications is sensible. Another recent paper using such indices is Berti et al. (2012). Here, the signalling approach is used in order to construct fiscal stress indexes for the EU and nine more advanced economies. They

\footnotetext{
2 The theoretical framework is found at the work of Cottarelli (2011), where the three major reasons of government's rollover risks are analysed.

${ }^{3}$ Schaechter et al. (2012) provide a good example of how this kind of research can be used for policy making.
} 
include a number of macro-financial and competitiveness variables from those used by the EU policymakers. According to the empirical findings, the chosen variables perform well as leading indicators of fiscal stress episodes. Also, the results are improved whenever the aggregate stress indexes are incorporated to the model, compared to the single indicators.

\section{Methodology}

\subsection{The Financial and Fiscal Stress Indices}

We compute a number of financial and fiscal stress indices. These indexes are used in the empirical analysis in the next section. Their major advantage, compared to stand alone indicators, is the ability to capture different sources of instability that can lead to episodes of financial turmoils and fiscal strain, into one single variable. Thus, a more accurate representation of the economic and financial conditions is offered, while the effects of many different financial markets (in the case of the FSIs) and fiscal vulnerability indicators (in the case of FiscSIs) are offered. Thus, we are capable of empirically investigating the relationships between financial and fiscal stress.

In more detail, the financial stress indexes are constructed followed the equalvariance approach, propagated by Cardarelli et al. $(2008,2011)$. According to this, the FSI is a composite indicator, in which each variable is added with its standardized value. That is, we deduct the mean and divide by its standard deviation. In this way, measurement problems are avoided, while the contribution of each single indicator is measured to deviations from its mean value. Finally, we assign an equal weight to each one of the contributors to the aggregate index. Even if the relevant literature is abundant of different methodologies in the index aggregation, it is evident that the 
equal-variance approach is as efficient as any other methodology, in terms of the accurate depiction of financial stress episodes ${ }^{4}$.

The variables included here are factors representing uncertainty in the markets, like the banking sector beta. This is calculated as the ratio of the moving covariance of year-over-year percentage change of each country's banking sector equity index, with the general equity index, over the moving variance of the general stock index. Then, the TED spread is the difference between the uncovered (3-month LIBOR) and covered (respective Treasury bill rate) investments for the interbank markets. Additionally, the inverted term spread (Treasury bill rate difference from the long-term government bond yield) is used. Both are important liquidity risk indicators. Corporate bond spread, defined as the yield difference of the long-term corporate bonds from the governmental ones, together with stock returns and the stock returns volatility (calculated as a $\operatorname{GARCH}(1,1)$ model of the general equity index, modelled as an autoregressive process with 12 lags) are the securities markets indicators. Finally, the real effective exchange rate volatility is also included. In a nutshell, the mathematical representation of the financial stress index is the following:

$$
\begin{aligned}
\text { FSI }= & \beta+\text { TED spread }+ \text { Inverted term spread }+ \\
& \text { Corporate Bond spread }+ \text { Stock market returns }+ \text { Stock market volatility }+ \\
& \text { Exchange rate market volatility }
\end{aligned}
$$

Turning to the fiscal stress indices, the aggregation approach is similar, while the metrics involved are representative of the three important characteristics; 1 ) the fiscal burden of the economy, 2) the long term trends on their fiscal position (based on the fertility rate and the governmental funding needs for social security issues) and 3) each country's financing needs. Based on the work of Baldacci et al. (2011a) and the data availability for the countries included in this study, our indices consist

\footnotetext{
${ }^{4}$ An excellent survey of the aggregation approaches for the financial stress indices is provided by Kliesen et al. (2012).
} 
of five variables. In the first case, the difference of the government debt payments rate $(r)$ from the growth rate of the economy $(g)$. This indicator offers a clear idea of the degree of economy's solvency and whether or not it is close to a fiscal crisis. Apparently, an economy needs to service its debt obligations and its ability to do it depends on the level of its growth rate. Then, we also include the general government structural balance, which is defined as the cyclically adjusted balance, including any temporary revenue or expenditure items. Finally, the general government net debt is calculated as the difference between the gross debt of the country from any relevant financial assets that correspond to debt instruments. All three variables are expressed as percentages of the country's GDP.

The last two variables concern the long term fiscal trends. Here, total fertility rate and the old age dependency ratio are used. The former is the average number of children per woman, while the latter reflects the projected calculations for the share of population that will be over 65 in the next 30 years, as a percentage of the total adult population. Both variables are crucial because they offer projections on the tax base of the economies, together with the number of people able to contribute to the fiscal sustainability of a country, through their contribution to the healthcare and pension systems.

The aggregation method is similar to the one followed for the financial stress index. The only difference is that the mean and the standard deviation used are the 10-year peer group average. This formula can shortly be written as follows:

$$
\text { FiscSI }=(r-g)+\text { structural balance }+ \text { net debt }+ \text { fertility rate }+ \text { depedency ratio }
$$


Our sample is the G7 economies; Canada, France, Germany, Italy, Japan, United Kingdom and United States. The dataset consists of quarterly observations, covering a period from the beginning of 1980's until the second quarter of 20095 .

In order to verify whether our indices work well as timely indicators of the prevailing conditions in the financial markets and the fiscal condition of an economy, we plot them in two separate graphs. Figure 1 depicts the G7 financial stress indexes, while Figure 2 the fiscal stress ones. Regarding Figure 1, it is easy to observe a strong co-movement of the indices throughout the period examined. There are some variations, though, especially in periods where a financial crises episode hit specific economies. For instance, Italy and UK stress indices achieved their, second to the current crisis, highest values during the ERM crisis period, while the Asian crisis of 1997-99 has strongly affected all the economies of our sample. Without any doubt, the biggest effect on G7 financial conditions is the one from the current financial crisis that initiated in 2007.

\section{Put Figure 1 here}

Especially after the third quarter of 2008, which coincides with the Lehman Brothers collapse, the stress indexes reach their most extreme values. The level of financial stress at that period was unprecedented and it justifies the decision of the governments to heavily intervene in the financial markets. Gradually, the indexes decrease towards the end of the sample period. Nevertheless, they still remain in relatively high stress level.

A similar situation is observed in Figure 2. In all cases, the fiscal conditions of the G7 countries significantly deteriorated during the current crisis. It is also evident that this deterioration has begun earlier for most of the economies. Probably, this is a sign of the troubled public finances the developed economies face, due to a number of reasons, such as the ageing population and the anaemic rates of growth. Japan is

\footnotetext{
${ }^{5}$ In some cases, some annual observations were interpolated into quarters. Depending on the country, the dataset range varies. The time period examined is until 2009Q2 due to data limitations.
} 
an interesting case, since it seems to be quite prudent during the previous three decades but, in the last ten years, its fiscal position becomes gradually worse than most of the rest. Canada and Germany, although affected by the current crisis,

\section{Put Figure 2 here}

they successfully managed their macroeconomic imbalances. On the other hand, UK has improved its performance only in the last decade, while France and USA were always more fiscally vulnerable that the other economies of the group.

\subsection{Related SVAR Literature and Model Specification}

Apart from its domination in literature concerning the effect of monetary policy, SVAR analysis has become the empirical tool for investigating the effects of fiscal policy as well. Caldara and Kamps (2008) provide an extensive survey of this literature. In spite of a great number of different model specifications, only a small proportion of papers go beyond the study of fiscal policy. More precisely, an interesting topic is the examination of interrelations between fiscal variables and the financial stress as measured by the FSI. Afonso et al. (2011) examine how fiscal and financial shocks affect the macroeconomy. In this study, the distinction between low and high financial stress periods is captured by employing a threshold VAR model for the US, UK, Italy and Germany. Among their outcomes, they find that economic growth responds positively to fiscal shocks in both regimes. On the other hand, growth has a negative response to financial shocks.

In a related paper, which, however, does not belong to the fiscally related VAR literature, Mallick and Sousa (2013) examine the macroeconomic impact of monetary policy and financial stress shocks. Using two alternative SVAR identification methods, their results support the negative growth effects from a financial shock. In this study, we work on a similar framework. Employing a SVAR model, we try to look into the effects of both financial and fiscal shocks. The structural VAR model is written as: 


$$
A X_{t}=A_{0}+A_{1}(L) X_{t-1}+B e_{t}
$$

$X_{t}$ is the vector of the 6 endogenous variables given by $X_{t}=\left[f_{t}, s_{t}, y_{t}, \tau_{t}, i_{t}, n_{t}\right]$, where $f_{t}$ is the FSI, $s_{t}$ is the FiscSI, $y_{t}$ is the growth of real GDP, $\pi_{t}$ is the inflation rate, $i_{t}$ is the short-term interest rate $^{6}$ and $n_{t}$ is the nominal effective exchange rate (NEER, hereafter $)^{7} . A$ is the matrix of autoregressive coefficients of order $6 \times 6$ and $e_{t}$ is the vector of structural disturbances. We estimate the VAR model setting $p=4$ lags as this is the most appropriate choice for quarterly data. Using the number of lags, determined by the Schwarz and Hannan-Quinn criteria, does not change the results ${ }^{8}$.

Following Cover and Mallick (2012) we use a recursive causal structure so as to impose the necessary number of restrictions that enables to estimate the SVAR. This particular ordering reveals our assumptions. Firstly, we assume that a FSI shock can be quickly transmitted to all sectors of the economy. This means that all the examined variables start to respond in the first quarter. In this way, the FSI is ordered as first variable. Secondly, we assume that an unexpected increase in the FiscSI starts to affect the growth rate, the inflation, the interest rate and the nominal effective exchange rates at the same quarter. The FiscSI shock affects the FSI after one quarter. So, the FiscSI is order as second variable in the SVAR model. Consequently, we assume that growth shocks affect at the same period the inflation and the interest rate as well as the nominal effective exchange rates. However, the effects of growth shocks affect the financial and fiscal stress indexes after one quarter; the growth rate is ordered as third variable. Furthermore, inflation shocks affect simultaneously only interest rates and exchange rates. Similarly, interest rates shocks affect simultaneously only the exchange rates. So inflation and interest rates are ordered as

\footnotetext{
${ }^{6}$ All data, apart from FSI and FiscSI which are constructed by us, come from International Financial Statistics provided by the IMF. The inflation is the GDP deflator. As short term interest rates we used the money market rates. Only for the case of France we used the treasury bill rates. The data for NEER are taken from the BIS database.

${ }^{7}$ We use this variable so as to take into account foreign exchange market shocks. We thank an anonymous referee for indicating this aspect.

${ }^{8}$ In order to save space, we present only the former estimates.
} 
the fourth and the fifth variable, respectively. Finally, we assume that the exchange rate shocks affect all the examined variables only with one lag. Assuming that $\varepsilon_{t}$ are the reduced-form residuals and $e_{t}$ are the structural shocks the recursive identification scheme can be summarised as:

$$
\varepsilon_{t}=\left(\begin{array}{c}
\varepsilon_{t}^{f} \\
\varepsilon_{t}^{s} \\
\varepsilon_{t}^{y} \\
\varepsilon_{t}^{\pi} \\
\varepsilon_{t}^{i} \\
\varepsilon_{t}^{n}
\end{array}\right)=\left(\begin{array}{cccccc}
x_{11} & 0 & 0 & 0 & 0 & 0 \\
x_{21} & x_{22} & 0 & 0 & 0 & 0 \\
x_{31} & x_{32} & x_{33} & 0 & 0 & 0 \\
x_{41} & x_{42} & x_{43} & x_{44} & 0 & 0 \\
x_{51} & x_{52} & x_{53} & x_{54} & x_{55} & 0 \\
x_{61} & x_{62} & x_{63} & x_{64} & x_{65} & x_{66}
\end{array}\right)\left(\begin{array}{c}
e_{t}^{f} \\
e_{t}^{s} \\
e_{t}^{y} \\
e_{t}^{\pi} \\
e_{t}^{i} \\
e_{t}^{n}
\end{array}\right)
$$

where $x_{i j}$ 's are the coefficients to be estimated.

\section{Empirical Evidence}

\subsection{The effects of financial stress shock}

We start our analysis focusing on the effects of a positive one standard deviation FSI shock on growth rates. For almost all countries a drop of growth is detected. For Germany, Italy, UK and US the reduction is sudden and the equilibrium is restored around 7 quarters later. For Japan the drop in growth rates is smoother and its duration is longer as it lasts for 12 quarters. For Canada the response of growth to a FSI shock remains around zero for 4 quarters after the shock. After that period a small increase takes place. The only exception is France where an increase of growth for 4 quarters is observed. After that period, the growth drops and after the $12^{\text {th }}$ quarter starts returning back to the equilibrium. The general picture of the above analysis is that a shock in the financial stress affects negatively growth rates. These results are consistent with economic theory and recent facts. Increasing financial 
stress reflects on the credit conditions of the economy. Therefore, the liquidity shortages abruptly affect the real economy and, thus, economic growth ${ }^{9}$.

The responses of inflation rates are also quite common across G7 economies. For Canada, France, Italy and US a significant drop of the inflation is observed. The equilibrium levels are restored around 9 quarters after the shock. UK experiences the most significant drop which reaches its maximum after 10 quarters. The only exception is Germany and Japan for which an increase takes place. However, this increase is mostly insignificant. Overall, the majority of the findings are sensible; the financial meltdown affects negatively the economic activity and the corresponding prospects. Consequently, this has an inverse effect on inflation.

Additionally, the impact on interest rates is also uniform across G7 economies; a decrease that is followed by an increase. More precisely, a decrease is observed for Canada, Italy, Japan, UK and US. In all these cases, the equilibrium is achieved after the period of $10^{\text {th }}$ quarter. Only in Canada the interest rate is back to its pre-shock level 4 quarters after the shock. For France and Germany the initial drop is not significant. Interestingly, we observe an increase in the interest rates after 8 and 11 quarters after the shock. Overall, we can claim that this outcome is a good depiction of the central banks' reaction after 2008; the interest rates gradually reduced.

Lastly, one standard deviation FSI shock causes the nominal effective exchange rate of UK pound and of US dollar to decrease. On the other hand, the corresponding value of the Japanese Yen is increased. On contrary the effects to the effective exchange rates of Euro (as this is reflected by the responses of France, Germany and Italy) and Canadian dollar are insignificant.

We now focus our analysis on the effects of a positive FSI shock on FiscSI. We assume that such a shock reflects the effects of an unexpected change in the

\footnotetext{
9 We also estimate our SVAR model, using IMF FSIs. The results remain similar and are available upon request.
} 
financial conditions over the current fiscal position. The estimated effects are characterised by large differences. For Canada, France, Germany and Italy the impulse response of the FiscSI die out very quickly with the whole movement being statistically insignificant. On the other hand, for UK and US economies a positive shock in FSI causes increasing FiscSI. This effect reaches its peak 7 quarters after the shock with the US response being more persistent than the UK one. Lastly, the case of Japan seems quite peculiar. The impulse response shows a constant decrease from the beginning without dying out. Despite this bizarre effect, the significant outcomes are in accordance to our expectation; a deterioration of the financial conditions reflects on the economies' fiscal stance. This is evident from the aftermath of the 2007-2009 financial crisis where the UK and US governments were forced to bail out the troubled financial institutions. As a result, the governmental balance sheets were heavily aggravated.

\section{Put Figures 3-9 here}

\subsection{The effects of fiscal stress shock}

We now stress our attention to the effects caused by an unexpected shock in the FiscSI. In a similar vein, the shocks of FiscSI are interpreted as unexpected changes of the prevailing fiscal conditions. These kinds of shocks may come from sudden changes in one or more index's components.

Focusing on the response of growth, a negative effect takes place. The most significant responses are observed for Canada, France, Japan and US. On average the negative effects die out after the first half of the examined periods. Like in the case of FSI shock, the growth is retarded whenever the economy experiences sudden fiscal strains.

As far as the response of inflation is concerned, all countries experience a decrease after the FiscSI shock. For Canada, Germany, UK, US the inflation rate 
constantly remain below the initial equilibrium levels. For France and Italy the initially reduced inflation increases after the $4^{\text {th }}$ and $6^{\text {th }}$ quarter, respectively. After reaching a peak, the responses tend to long-term level. Regarding the response of interest rate, Canada, Italy, Japan, UK and US experience a decrease in their interest rates. However, for Germany and France the response is mostly insignificant.

Furthermore, the value of the Canadian and American dollar decreases. The same is true for British pound decreases reaching the equilibrium just after 6 quarters. On the other hand, the value of Euro and the Yen remains the same; the oscillations around zero are insignificant.

Regarding the financial conditions, the most responsive indexes are those of Germany and UK. While for the UK the effects seem to remain at a constant level after the $3^{\text {rd }}$ quarter, an increasing trend appears for Germany. An increase is also observed for Italy. However, this initial increase lasts for 4 quarters, and subsequently the effect is reduced and gradually dies out. For US, Japan and France an initial increase is observed as well. Nevertheless, these effects remain insignificant. The only negative response is related to Canada; again this result is also insignificant for the examined period. Based on the above outcomes we observe that, at least of some of the G7 economies, the sovereign risks are related with the state of their financial markets.

\subsection{Historical Decompositions}

Beyond the impulse response analysis described above, we provide further evidence based on the historical decompositions. The purpose is to explore the individual contributions of financial and fiscal shocks to macroeconomic variables. To facilitate the comparisons we report the historical decompositions of the G7 economies for the three most important variables ${ }^{10}$. Figure 10 shows the contributions of FSI shock (red

\footnotetext{
10 We have omitted the corresponding diagrams for the NEER. The corresponding percentages were very small. The results are available upon request.
} 
bar) and FiscSI shock (green bar) to growth (blue line) across G7 economies. The right-hand side column measures the percentage of each contribution, while the lefthand side represents the rate of change. Firstly, our results suggest that both shocks have contributed to fluctuations of growth rates. This holds for all economies apart from Canada, where the fiscal shock has much stronger contribution than the financial one. Interestingly, for the latest quarters (2007Q3-2009:Q1) of our sample we observe that both financial and fiscal shocks have a negative contribution. So, during the period of financial crisis both shocks seem to have a dampening role to growth rates.

\section{Put Figure 10 here}

Figure 11 presents the historical decompositions for inflation. The general message is that fiscal shocks have a positive contribution when the inflation rises and a negative one when it falls, especially in Canada, Germany, Italy and Japan. Lastly, Figure 12 shows the corresponding decompositions for interest rates. Canada's short term interest rates seem to be mainly affected by fiscal shocks, while the French interest rates are mostly driven by financial shocks. For the remaining economies, both shocks contribute in a time-varying nature.

\section{Put Figure 11 here \\ Put Figure 12 here}

\section{Robustness and Further Evidence}

\subsection{Testing for Over-identifying Restrictions}

The analysis so far is based on a recursive identification scheme that was summarised by the equation (4). We now test for over-identifying restrictions. Firstly, we assume that a sudden increase in financial stress is not immediately transmitted to the fiscal stress indicator $\left(\mathrm{x}_{21}=0\right)$. Secondly, we assume that a shock in 
financial conditions does not affect the growth rate at the same period $\left(\mathrm{x}_{31}=0\right)$. Our third assumption is that monetary conditions, which are reflected by the response of interest rates, start to react only one period after a financial or fiscal shock $\left(\mathrm{x}_{51}=\mathrm{x}_{52}=0\right)$. The last step is to test these 4 assumptions at the same time $\left(\mathrm{x}_{21}=\mathrm{x}_{31}=\mathrm{x}_{51}=\mathrm{x}_{52}=0\right)$. Under this assumption, the restricted version of equation (4) is now written as:

$$
\varepsilon_{t}=\left(\begin{array}{c}
\varepsilon_{t}^{f} \\
\varepsilon_{t}^{s} \\
\varepsilon_{t}^{y} \\
\varepsilon_{t}^{\pi} \\
\varepsilon_{t}^{i} \\
\varepsilon_{t}^{n}
\end{array}\right)=\left(\begin{array}{cccccc}
x_{11} & 0 & 0 & 0 & 0 & 0 \\
0 & 0 & 0 & 0 & 0 & 0 \\
0 & x_{32} & x_{33} & 0 & 0 & 0 \\
x_{41} & x_{42} & x_{43} & x_{44} & 0 & 0 \\
0 & 0 & x_{53} & x_{54} & x_{55} & 0 \\
x_{61} & x_{62} & x_{63} & x_{64} & x_{65} & x_{66}
\end{array}\right)\left(\begin{array}{c}
e_{t}^{f} \\
e_{t}^{s} \\
e_{t}^{y} \\
e_{t}^{\pi} \\
e_{t}^{i} \\
e_{t}^{n}
\end{array}\right)
$$

Table 1 summarises the $p$-values of the above restrictions. For almost all cases, the null that the over-identifying restrictions are true is not rejected at $10 \%$ level. The impulse responses computed for the restricted version are actually the same with the ones reported in Figures 3-911.

\subsection{Sign Restrictions}

As a robustness check we follow a different identifying approach. Instead of assuming a specific ordering, we put certain restrictions on the impulse response functions, employing the pure sign restrictions method of Uhlig (2005). Given that our main focus is the macroeconomic consequences of financial and fiscal shocks we assume a positive sign on both FSI and FiscSI shocks. More precisely, a positive restriction is placed on both indexes for a period of three quarters. Given this assumption we focus on the responses of the remaining variables. Figures 10-16 show the median impulse responses along with the $16^{\text {th }}$ and $84^{\text {th }}$ quantiles. Starting from growth rates, the empirical results suggest a significant drop for Canada, Italy, Japan, UK and US. For Germany and France the drop is mostly insignificant. The

\footnotetext{
${ }^{11}$ To save space we do not report these impulse responses.
} 
results are also in accordance with the previous findings when we examine the response of the inflation. For almost all cases the inflation rates are reduced. However, the period when these negative effects die out is not the same across countries. Furthermore, for Germany an increase is observed. This result is also consistent with the previous evidence based on the recursive ordering. The same is also true for France.

Regarding interest rate responses, in the majority of the examined countries, interest rates decrease. This is again consistent with the precious findings. Interestingly, for Canada, Italy, and Japan the interest rates remain below the equilibrium for the whole examined period. For UK and US the effects die out 17 and 10 quarters after shock, respectively. For Germany and France the responses remain insignificant. The only kind of responses that vary across countries is the responses of the nominal effective exchange rates. For France, Germany and Japan an increase of exchange rate is observed. On contrary, we find a negative response for Canada and Italy. For UK, a small decrease takes place immediately after the shocks but 13 quarters later an increase is observed. For the US the mean response remain close to zero indicating no significant effect for the exchange rate.

\section{Put Figures 10-16 here}

Based on the above findings, we perform two alternative sign restrictions. This is done in order to examine the interactions between FSI and FiscSI. Firstly, we impose a positive FSI shock. We additionally assume that this shock affects negatively both growth and interest rates. The results suggest that in all cases, the FSI shock causes an increase to the FiscSI. Secondly, we assume a positive FiscSI shock assuming again that growth and interest rates respond negatively. In this case, in four out of seven cases (Canada, Germany, UK, US), we find an increased response of the FSI. Overall, we observe that financial stress is transmitted directly to fiscal stress in all examined economies, while the opposite is not always the case. 


\section{Discussion and Conclusions}

In this paper we examine the macroeconomic effects from a financial and a fiscal stress shock as well as the interactions between these two sectors. The current crisis indicates that the sole investigation of financial and fiscal conditions is not enough for a well-rounded assessment of the global crisis episodes. In order to evaluate these two kinds of shocks we construct a financial stress indicator and the corresponding fiscal one for the G7 economies. In this way, we can assess the level and the evolution through time of the prevailing conditions of financial and fiscal sectors. The indexes perform quite well, based on their success to capture past and recent crisis episodes.

The analysis is based on a SVAR model. We use two different identification methods; a recursive ordering and pure sign restrictions. Our results reveal that transmission of a financial shock to fiscal sector and the opposite is not so pronounced. Additionally, we look into the effects on GDP growth, inflation, shortterm interest rates and exchange rates. The results suggest a negative response of growth to a sudden increase of both stress indicators. For the majority of the G7 economies these responses are persistent.

On the same vein, inflation rate respond negatively to both financial and fiscal shocks. Especially, in the case of excessive financial stress the inflation significantly drops. Regarding the interest rates, we observe that a fiscal deterioration dampens their level. The same holds for the case of increasing financial stress. However, after some period they tend to increase. Finally, the results for the nominal effective exchange rate are rather mixed. A clear negative effect exists only for US dollar and UK pound.

In general our study emphasises the importance of financial and fiscal vulnerabilities in the developed economies. Especially, the negative effects of the previously mentioned shocks to the real economy constitute an additional important reason to focus on policies able to contain their impact. The current efforts to 
formulate adequate macro-prudential policies together with the potential implementation of fiscal rules show that policy makers realise the existence of the complex dynamics between the financial and fiscal sectors. It would be interesting to extend this work through the examination of the potential transmission of financial and fiscal vulnerabilities across economies. 


\section{References}

Afonso, A., Baxa, J. and Slavik M., 2011. Fiscal Developments and Financial Stress: A Threshold VAR Analysis. ECB Working Paper, no. 1319.

Andrian, T., Estrella, A. and Shin H. S., 2010. Monetary Cycles, Financial Cycles and the Business Cycle. Federal Reserve Bank of New York Staff Report, no. 421.

Baldacci, E., McHugh, J. and Petrova I., 2011a. Measuring Fiscal Vulnerability and Fiscal Stress: a Proposed Set of Indicators. IMF Working Paper, no. 94.

Baldacci, E., Petrova, I., Belhocine, N., Dobrescu, G. and Mazraani S., 2011b. Assessing Fiscal Stress. IMF Working Paper, no. 100.

Berti, K., Salto, M. and Lequien M., 2012. An Early Detection Index of Fiscal Stress for EU countries. European Economy Economic Papers, no. 475.

Caldara, D. and Kamps C., 2008. What are the Effects of Fiscal Policy Schocks? A VAR-Based Comparative Analysis. ECB Working Paper, no. 877.

Cardarelli, R., Elekdag, S. and Lall S., 2008. Financial Stress and Economic Downturns. Chapter 4 of IMF World Economic Outlook, October.

Cardarelli, R., Elekdag, S. and Lall S., 2011. Financial Stress and Economic Contractions. Journal of Financial Stability, 7, 78-97.

Chen, X., Kontonikas, A. and Montagnoli A., 2012. Assets Prices, Credit and the Business Cycle. Economics Letters 117, 857-861. 
Claessens, S., Ayhan Kose, M. and Terrones, M. E., 2011. Financial Cycles: What? How? When? in: Clarida, R. and F. Giavazzi (eds.), NBER 2010 International Seminar on Macroeconomics, University of Chicago Press.

Claessens, S., Ayhan Kose, M. and Terrones M. E., 2012. How do Business and Financial Cycles Interact? Journal of International Economics 87, 178-190.

Cottarelli, C., 2011. The Risk Octagon: A Comprehensive Framework for Assessing Sovereign Risks. Presentation delivered at a seminar held at the Sapienza University in Rome.

Cover, J.P. and Mallick, S.K., 2012. Indentifying Sources of Macroeconomic and Exchange Rate Fluctuations in the UK. Journal of International Money and Finance $31,1627-1648$.

Drehmann, M., Borio, C. and Tsatsaronis K., 2012. Characterising the Financial Cycle: Don't lose sight of the Medium Term. BIS Working Papers, no. 380.

Hatzius, J., Hooper, P., Mishkin, F., Schoenholtz, K. and Watson M., 2010. Financial Conditions Indexes: A Fresh Look after the Financial Crisis. NBER Working Paper, no. 16150 .

Hemming, R. and Petrie M., 2000. A Framework for Assessing Fiscal Vulnerability. IMF Working Paper, no. 52.

Kannan, P., 2012. Credit Conditions and Recoveries from Financial Crises. Journal of International Money and Finance 31, 930-947.

Karfakis, C., 2013. Credit and Business Cycles in Greece: Is there any relationship?. Economic Modelling 32, 23-29. 
Kastrop, C., Ciaglia, S., Ebert, W., Stoberg, S. and Wolff-Hamacher S., 2012. Fiscal, Economic and Financial Vulnerabilities: Implications for the Euro Area Surveillance Framework, paper presented at the Banque de France conference on Macroeconomic and Financial Vulnerability Indicators in Advanced Economies.

Kliesen, K., Owyang, M. and Vermann E., 2012. Disentangling Diverse Measures: A Survey of Financial Stress Indexes, Federal Reserve Bank of St. Louis Review, 94, 369-397.

Mallick, S. and Sousa R., 2013. The Real Effects of Financial Stress in the Eurozone. International Review of Financial Analysis 30, 1-17.

Tagkalakis, A., 2012. The Effects of Financial Crisis on Fiscal Positions. European Journal of Political Economy 29, 197-213.

Uhlig, H., 2005. What are the Effects of Monetary Policy on Output? Results from an Agnostic Identification Procedure. Journal of Monetary Economics 52, 381-419. 


\section{Figures}

Figure 1: G7 Financial Stress Indices

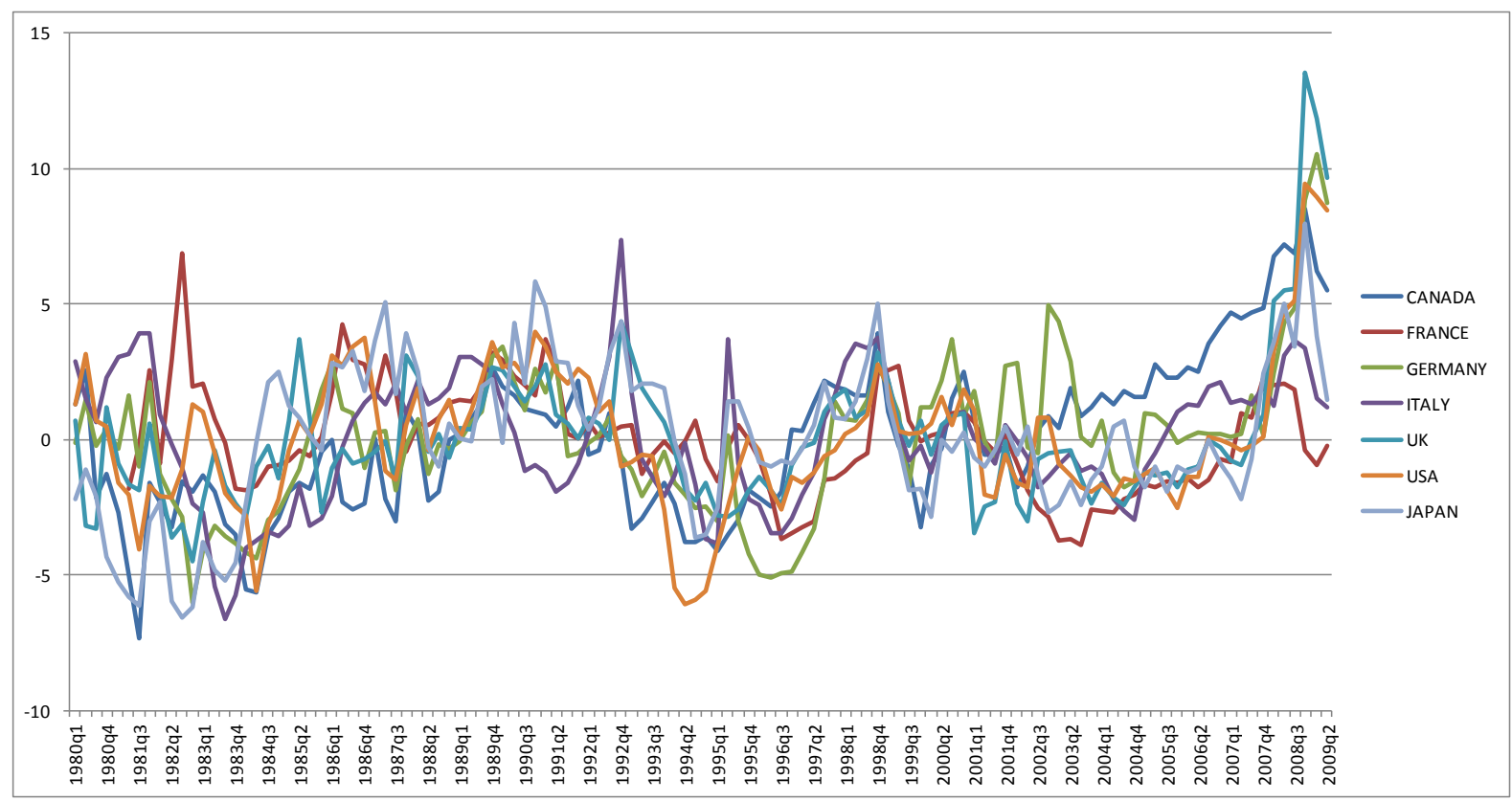

Data Sources: Authors' calculations

Figure 2: G7 Fiscal Stress Indices

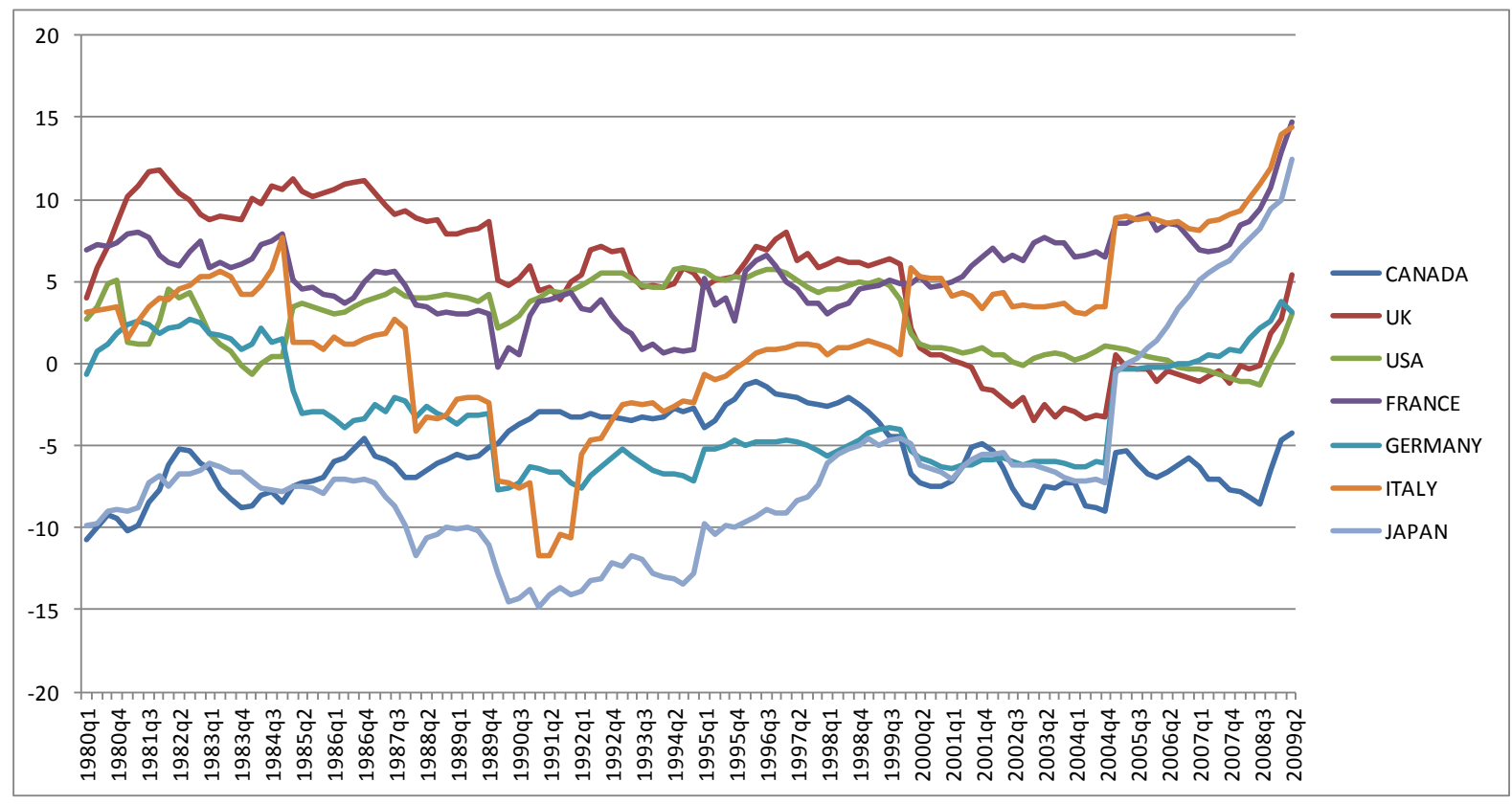

Data Sources: Authors' calculations 
Figure 3: Canada Impulse Responses using recursive ordering

Response to Structural One S.D. Innovations \pm 2 S.E.

Response of Growth to FSI Shock

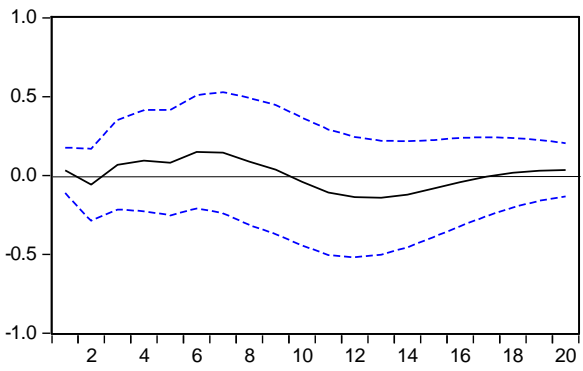

Response of Inflation to FSI Shock

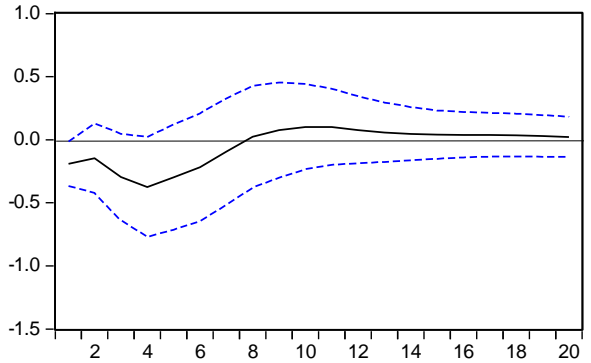

Response of Interest Rate to FSI Shock

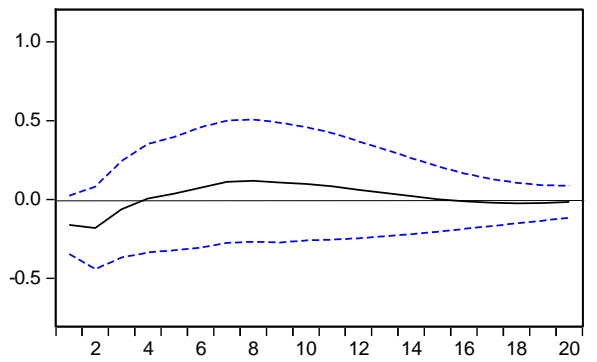

Response of NEER to FSI Shock

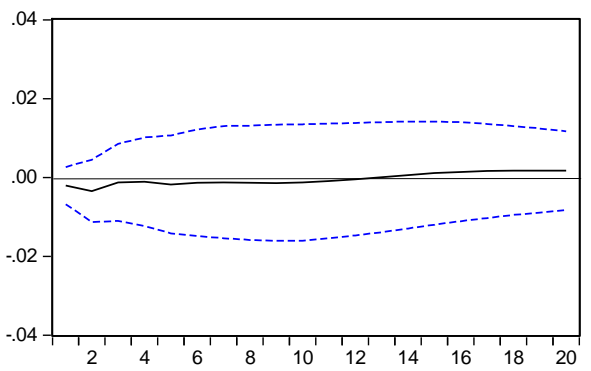

Response of FiscSI to FSI Shock

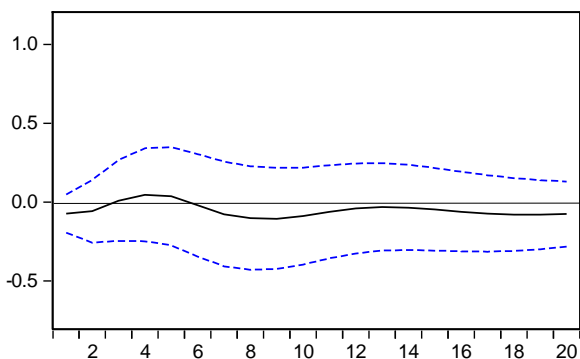

Response of Growth to FiscSI Shock

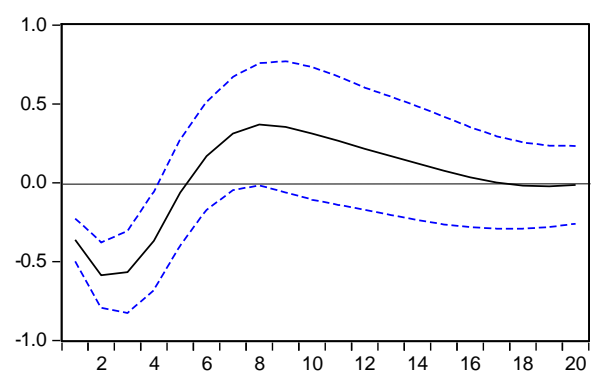

Response of Inflation to FiscSI Shock

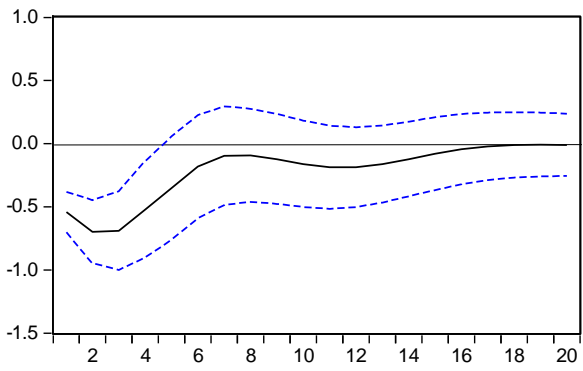

Response of Interest Rate to FiscSI Shock
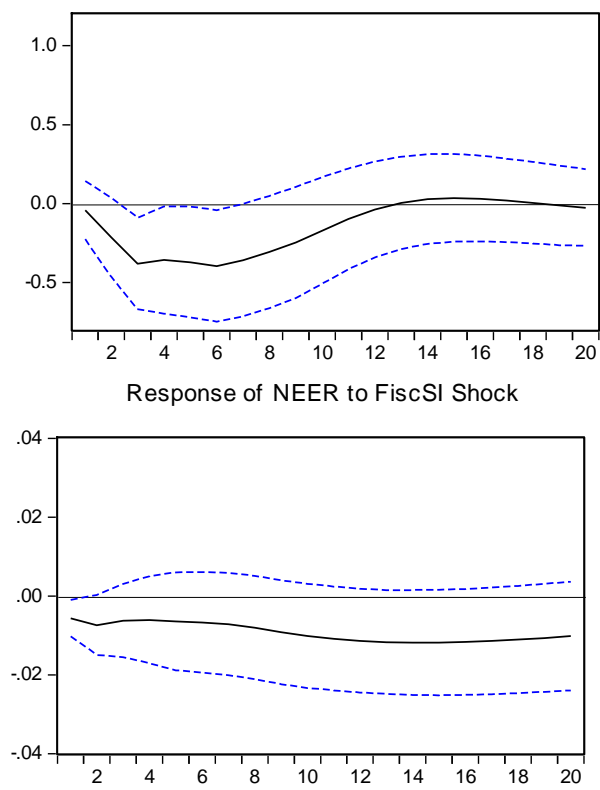

Response of FIN to FiscSI Shock

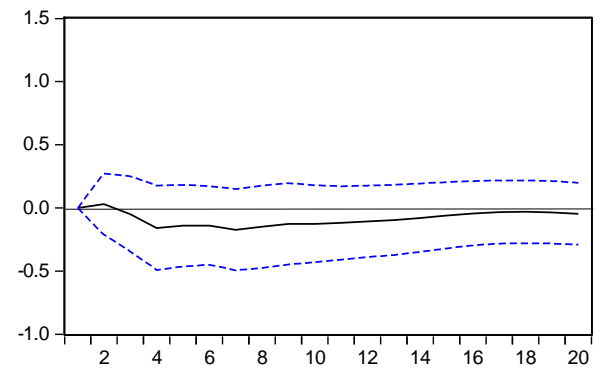


Figure 4: France Impulse Responses using recursive ordering

Response to Structural One S.D. Innovations \pm 2 S.E.

Response of Growth to FSI Shock
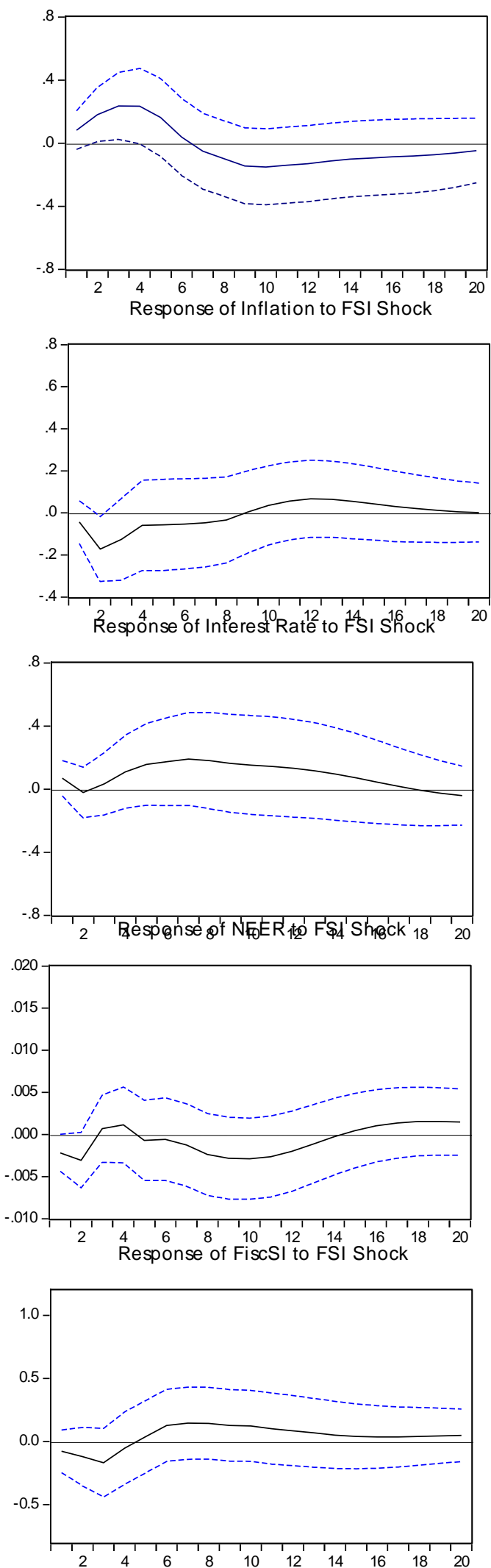

Response of Growth to FiscSI Shock
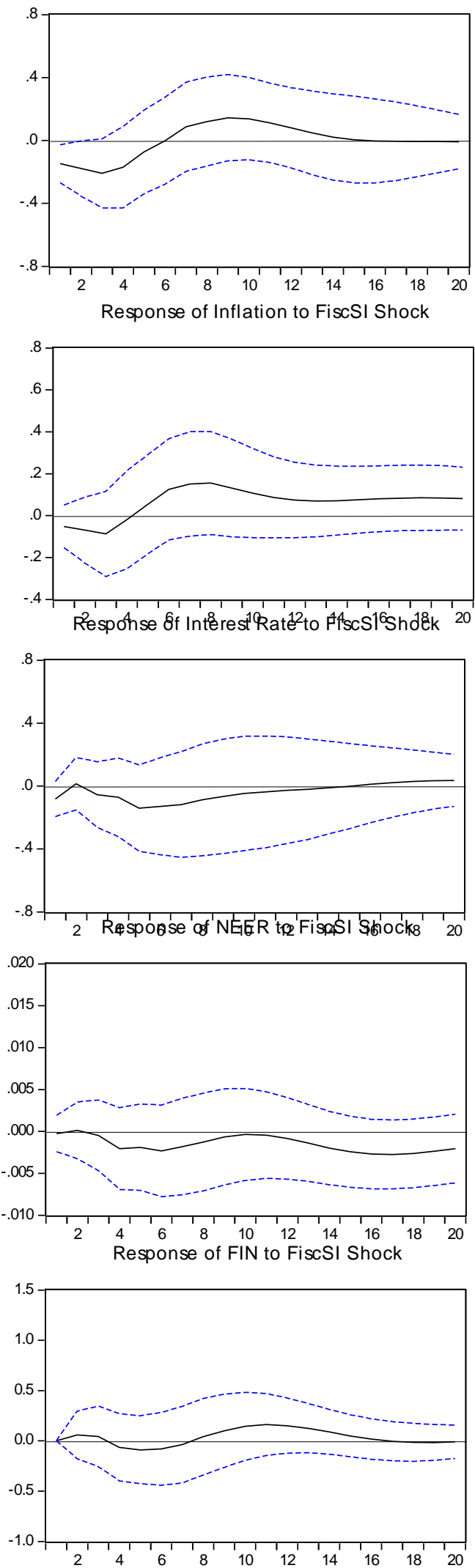
Figure 5: Germany Impulse Responses using recursive ordering

Response to Structural One S.D. Innovations \pm 2 S.E.

Response of Growth to FSI Shock
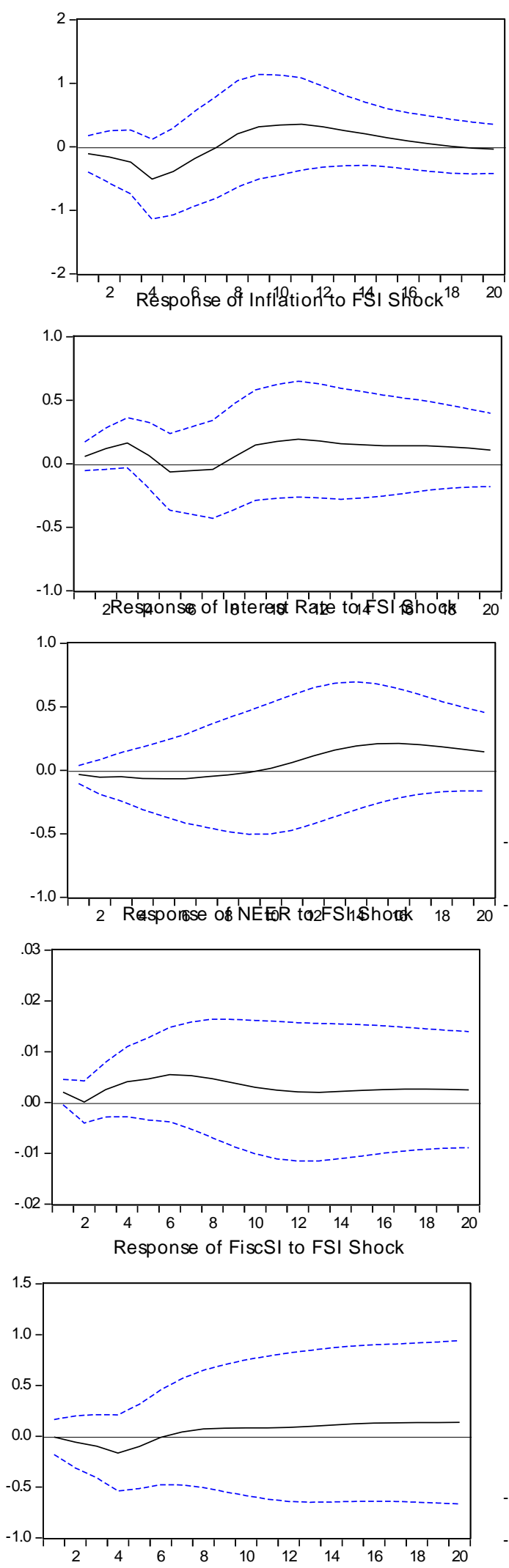

Response of Growth to FiscSI Shock
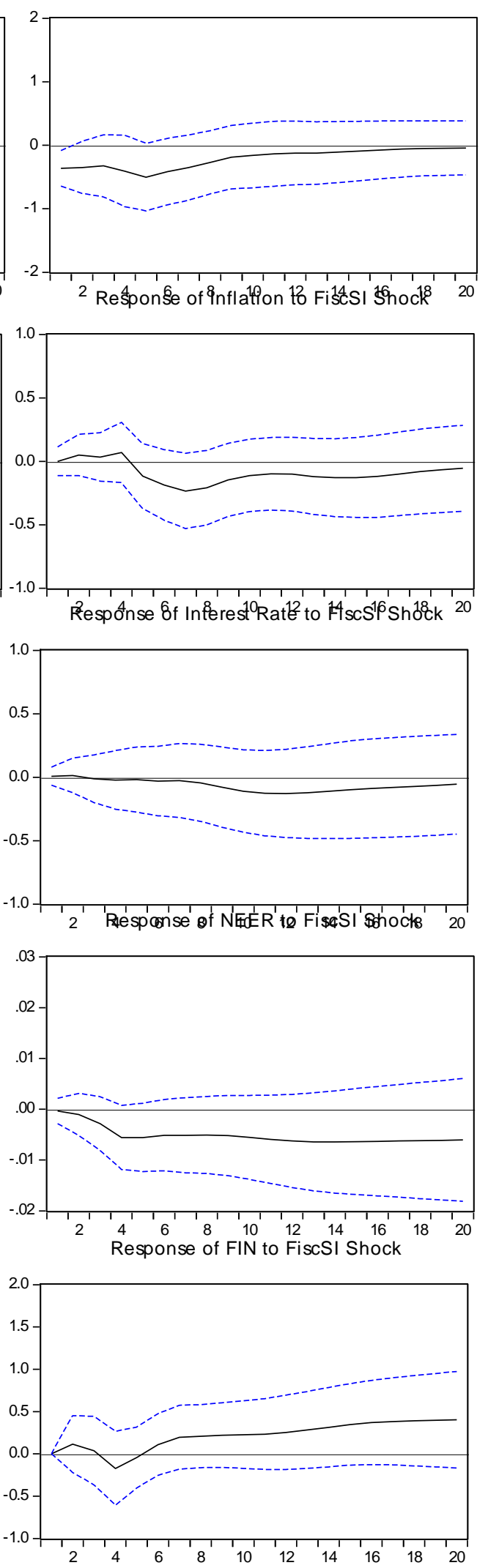
Figure 6: Italy Impulse Responses using recursive ordering

Response to Structural One S.D. Innovations \pm 2 S.E.

Response of Growth to FSI Shock
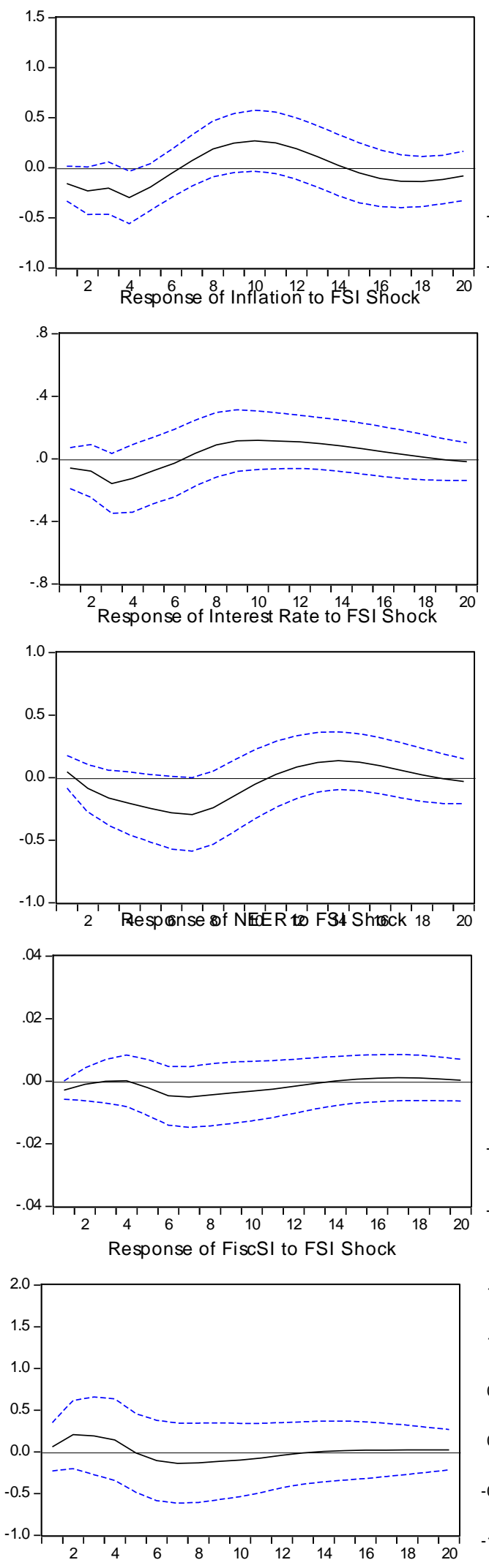

Response of Growth to FiscSI Shock
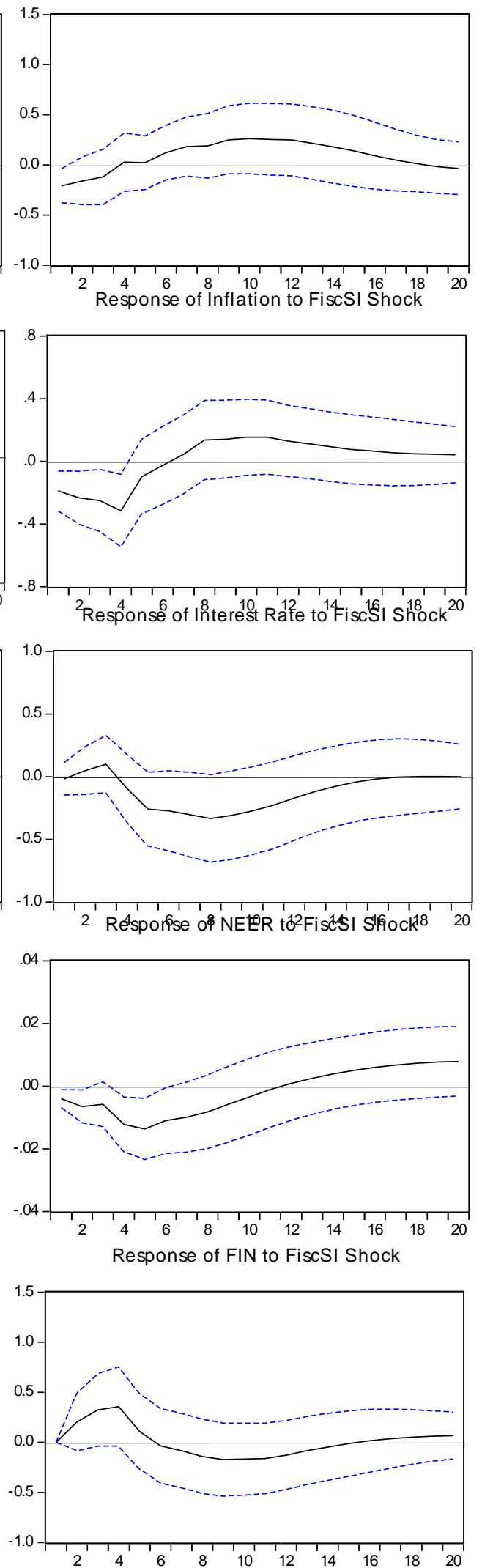
Figure 7: Japan Impulse Responses using recursive ordering

Response to Structural One S.D. Innovations \pm 2 S.E.

Response of Growth to FSI Shock
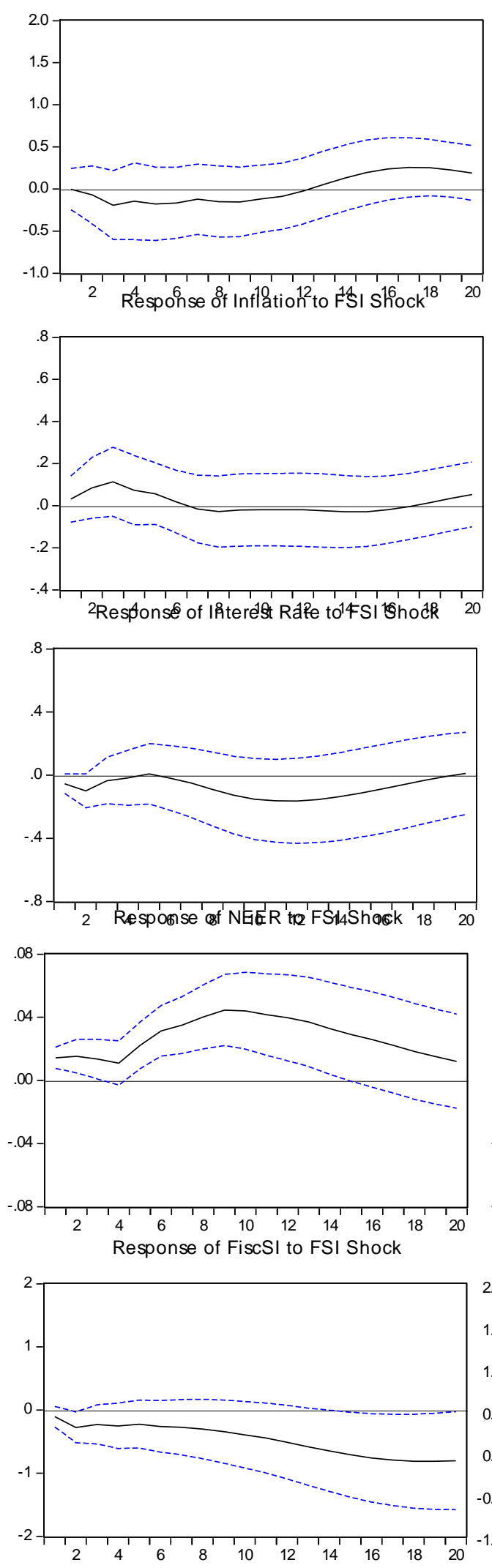

Response of Growth to FiscSI Shock
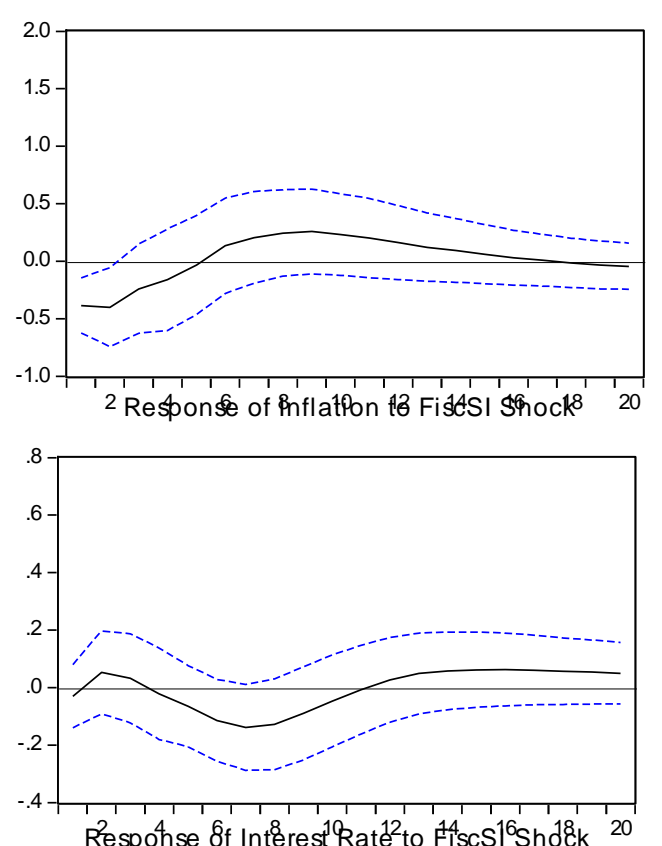

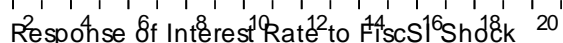
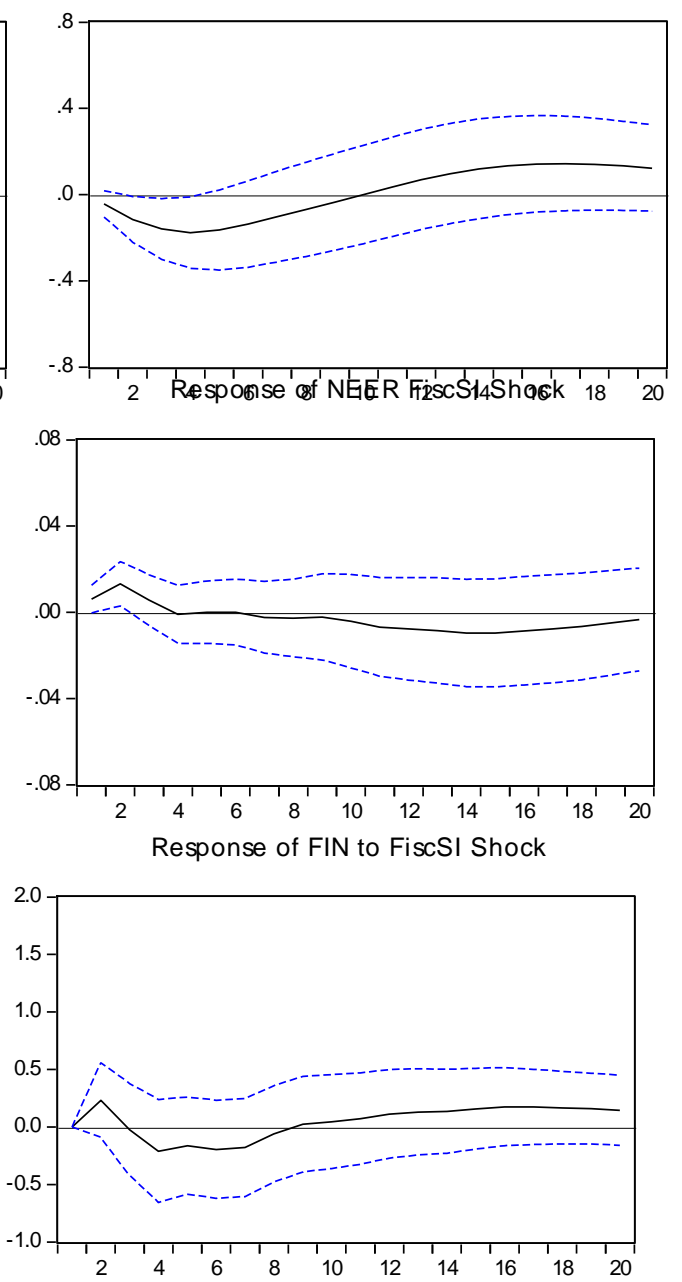
Figure 8: UK Impulse Responses using recursive ordering Response to Structural One S.D. Innovations \pm 2 S.E.

Response of Growth to FSI Shock
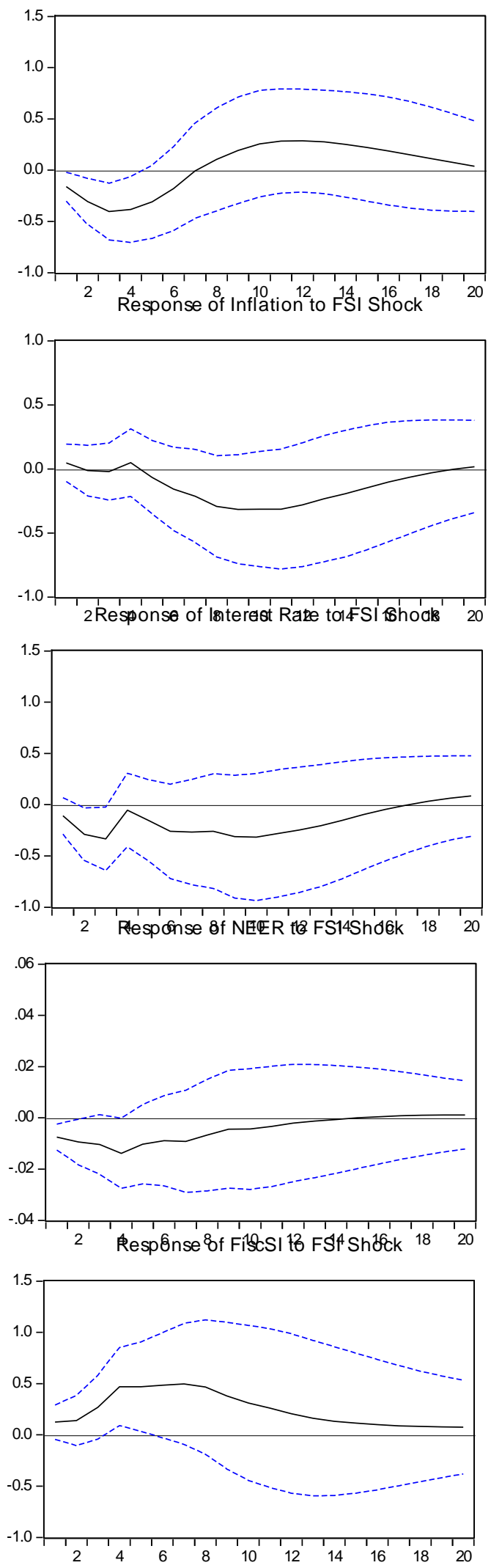

Response of Growth to FiscSI Shock
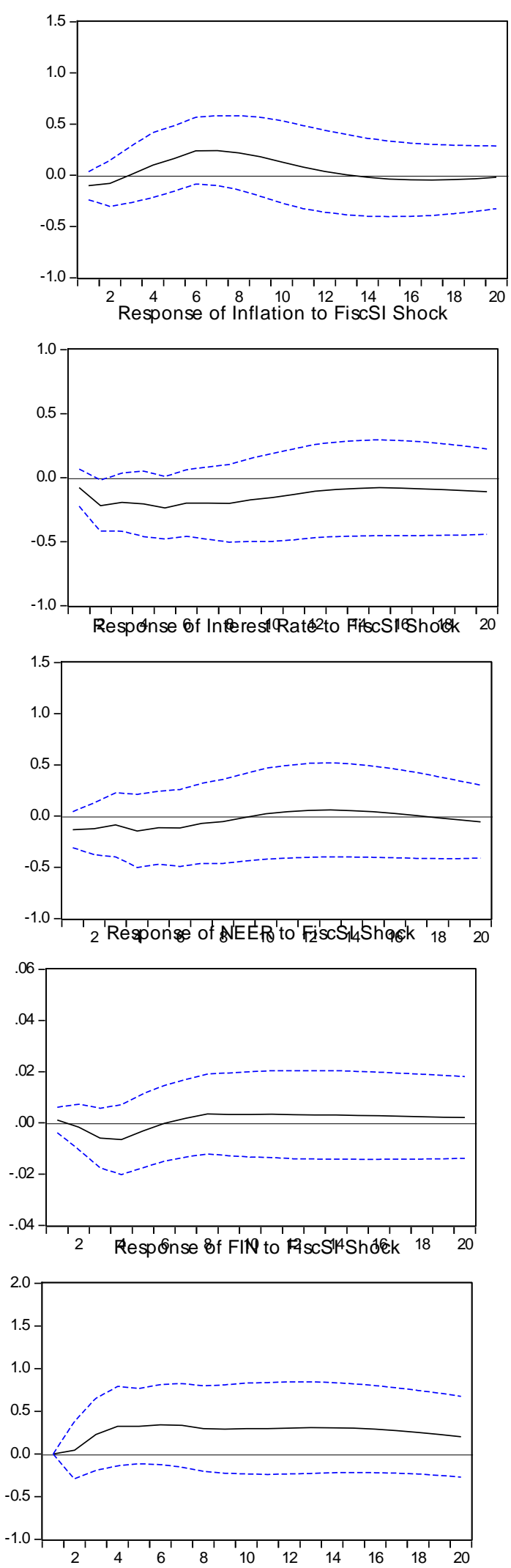
Figure 9: US Impulse Responses using recursive ordering Response to Structural One S.D. Innovations \pm 2 S.E.

Response of Growth to FSI Shock
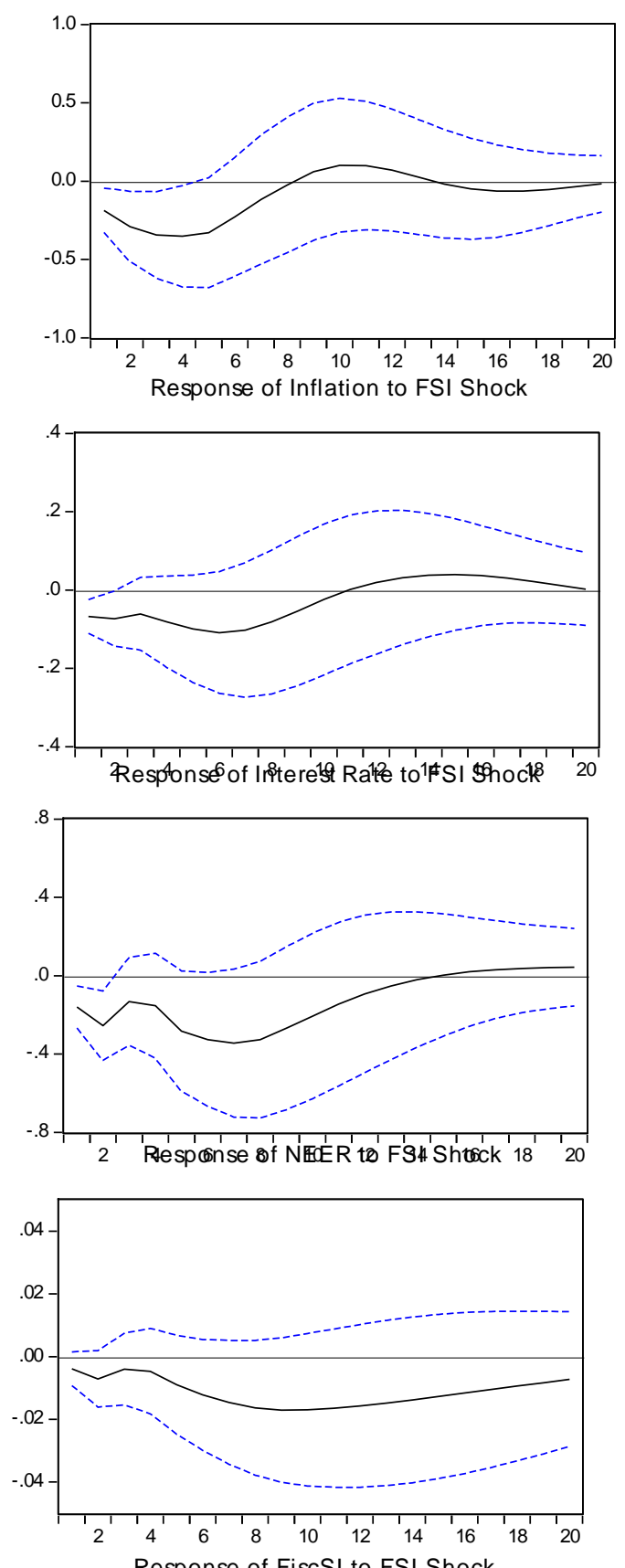

Response of FiscSI to FSI Shock

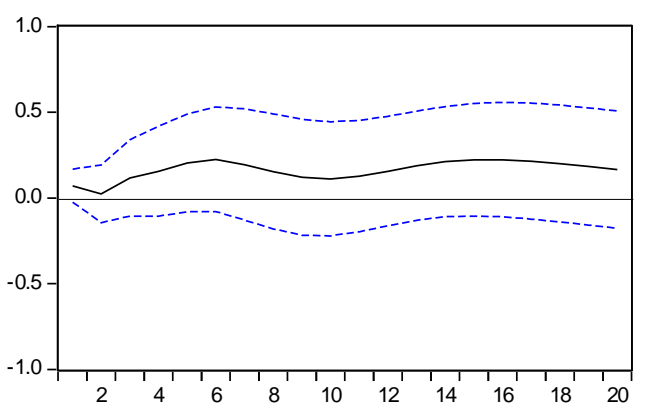

Response of Growth to FiscSI shock
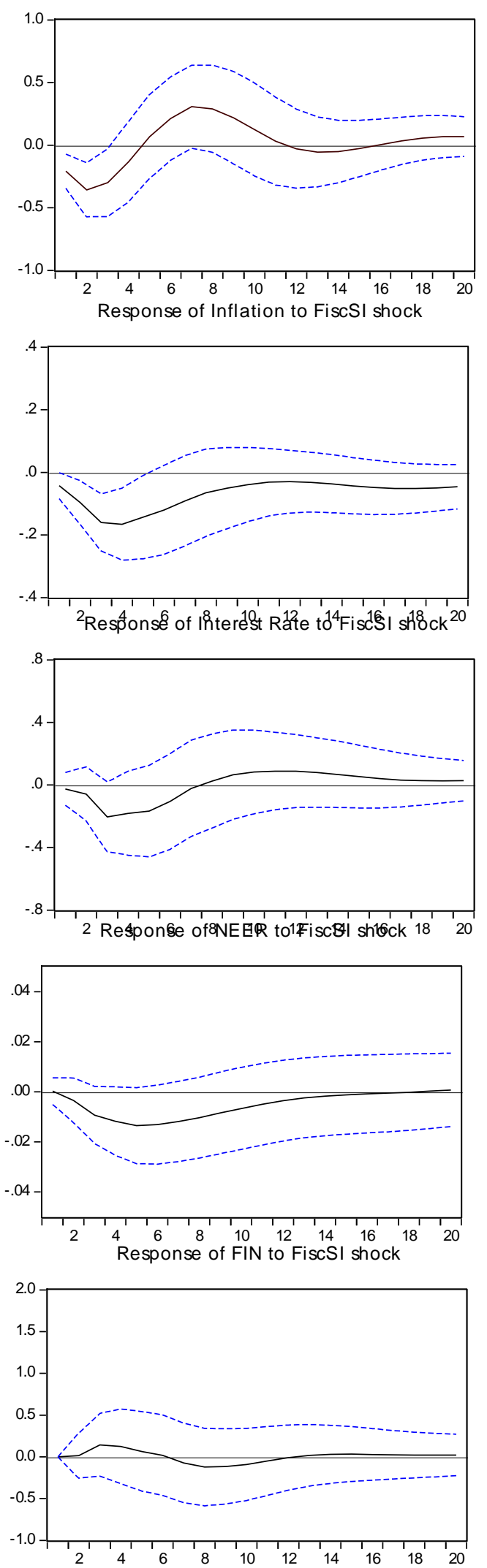
Figure 10: Historical Decompositions of Growth Rates

Canada

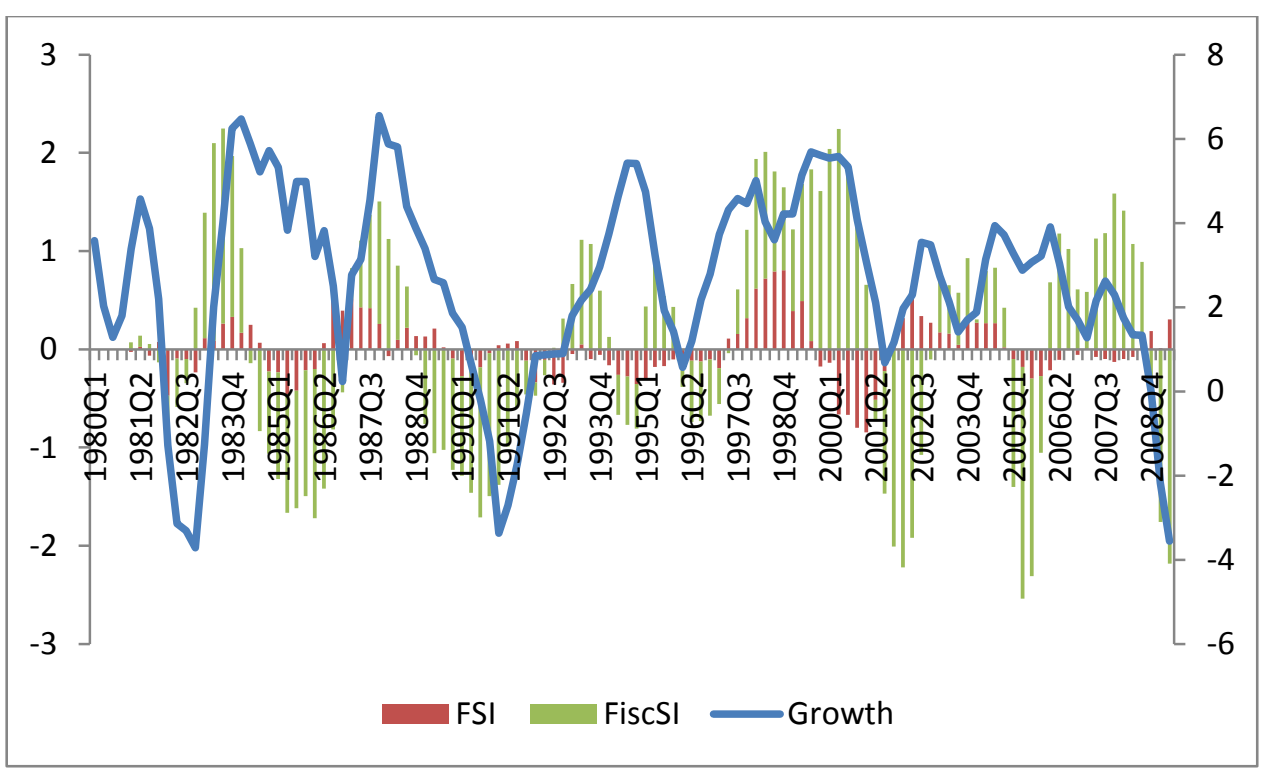

France

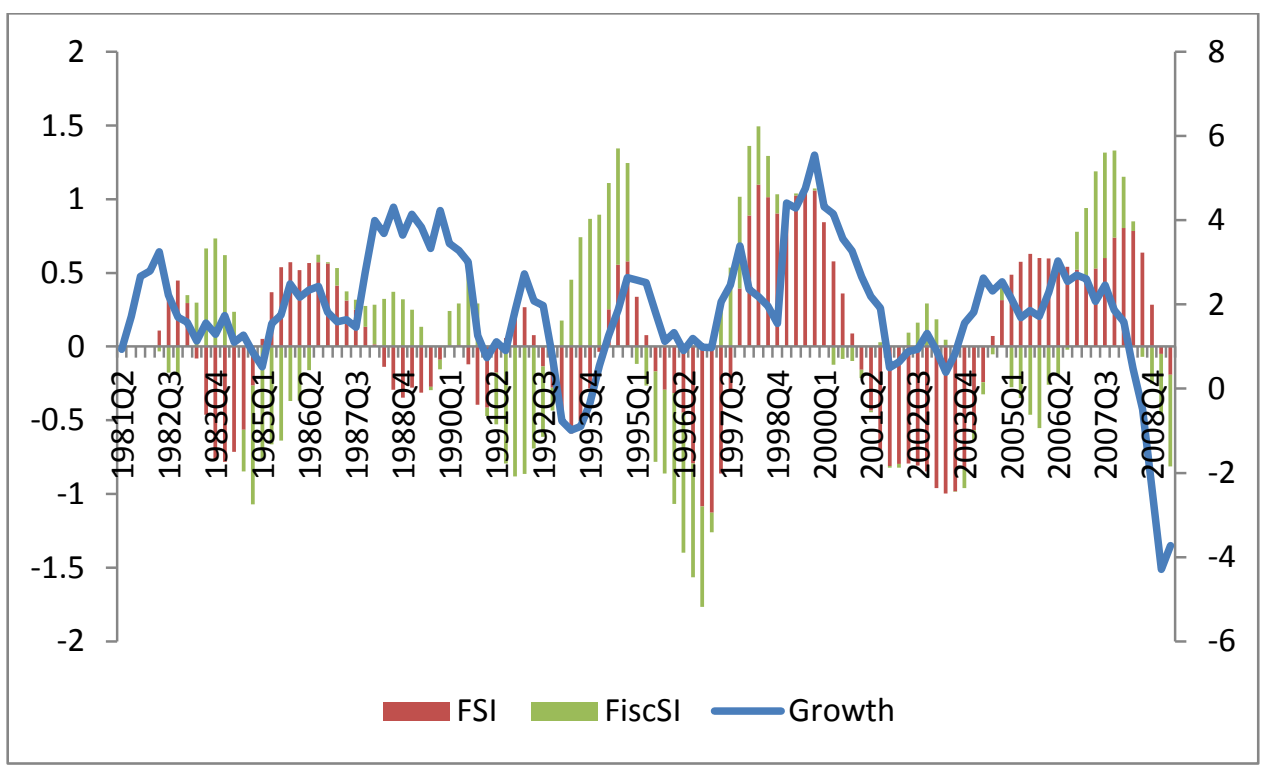


Germany

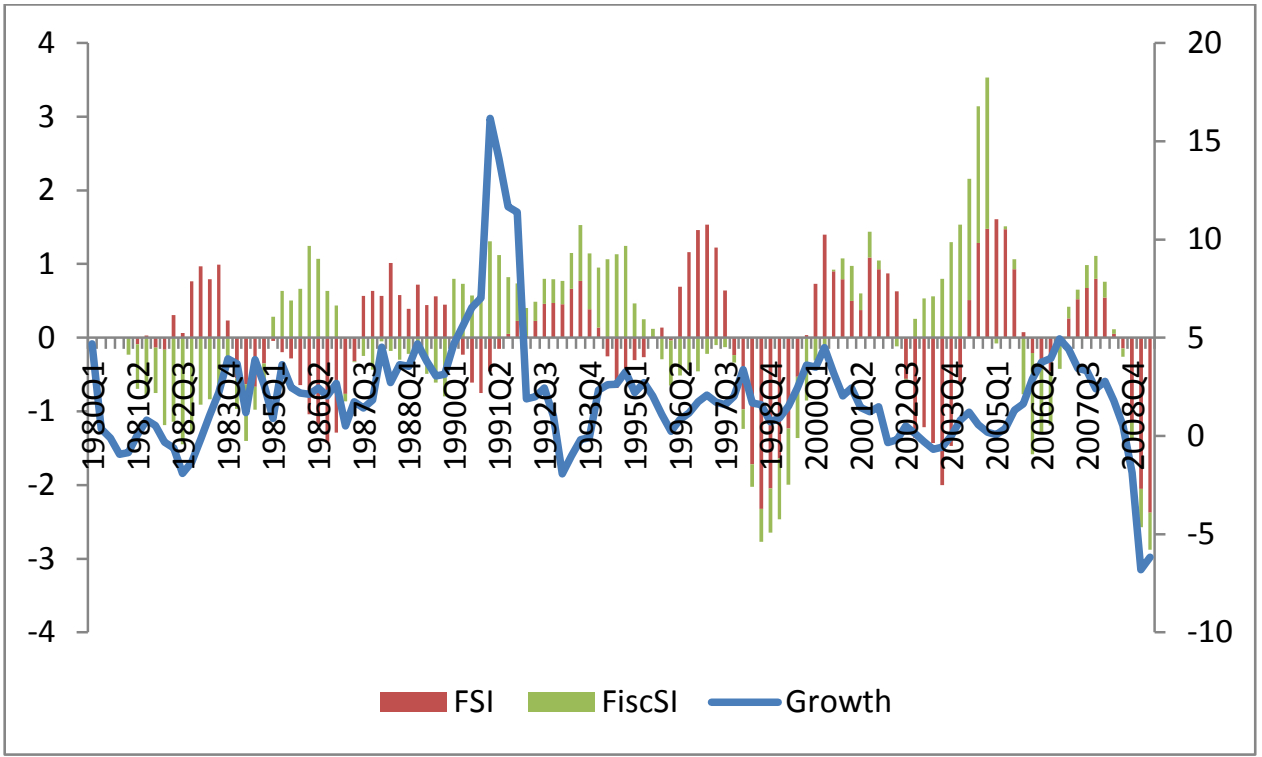

Italy

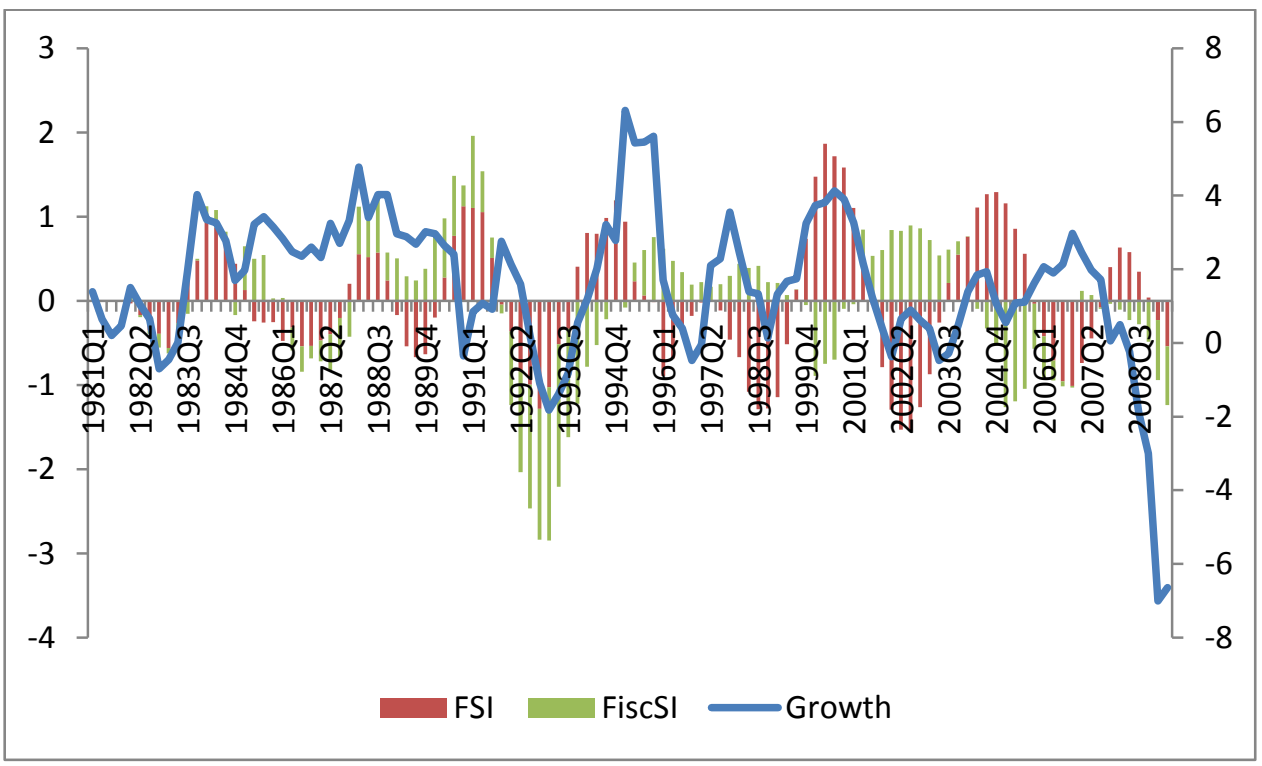


Japan

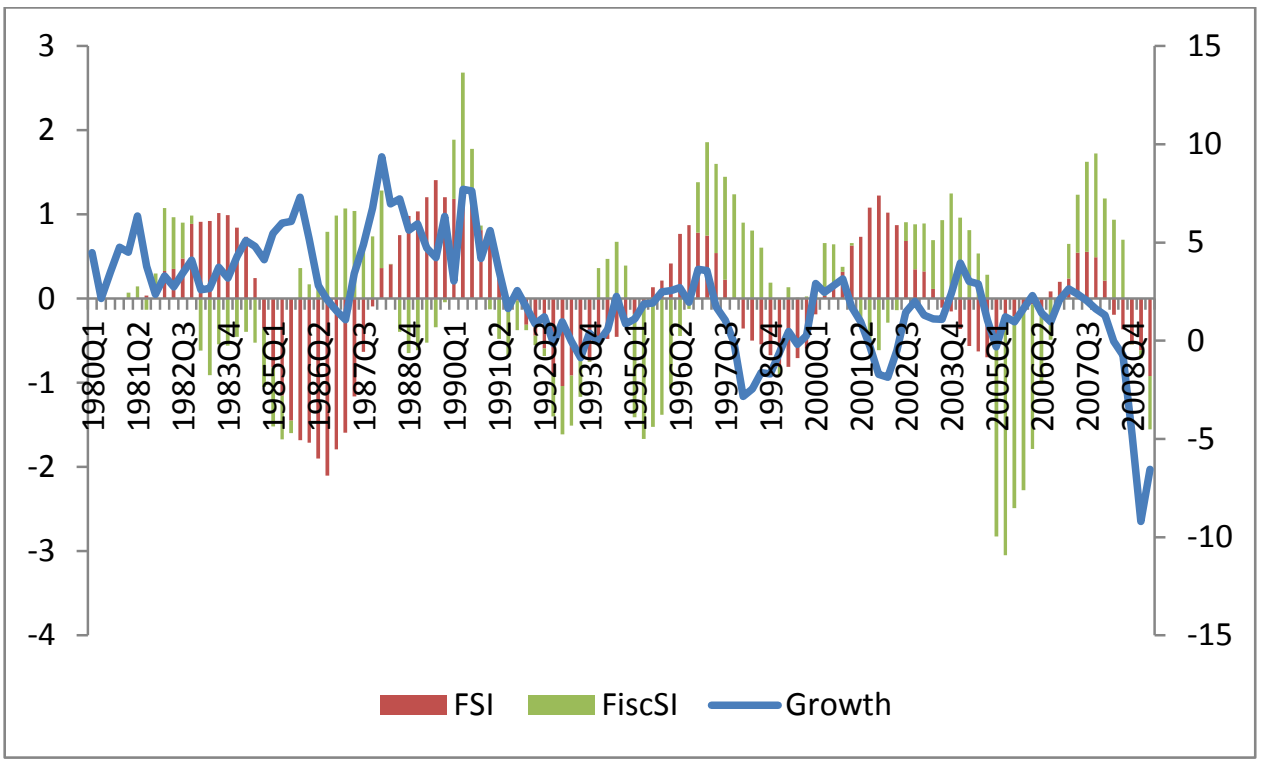

UK

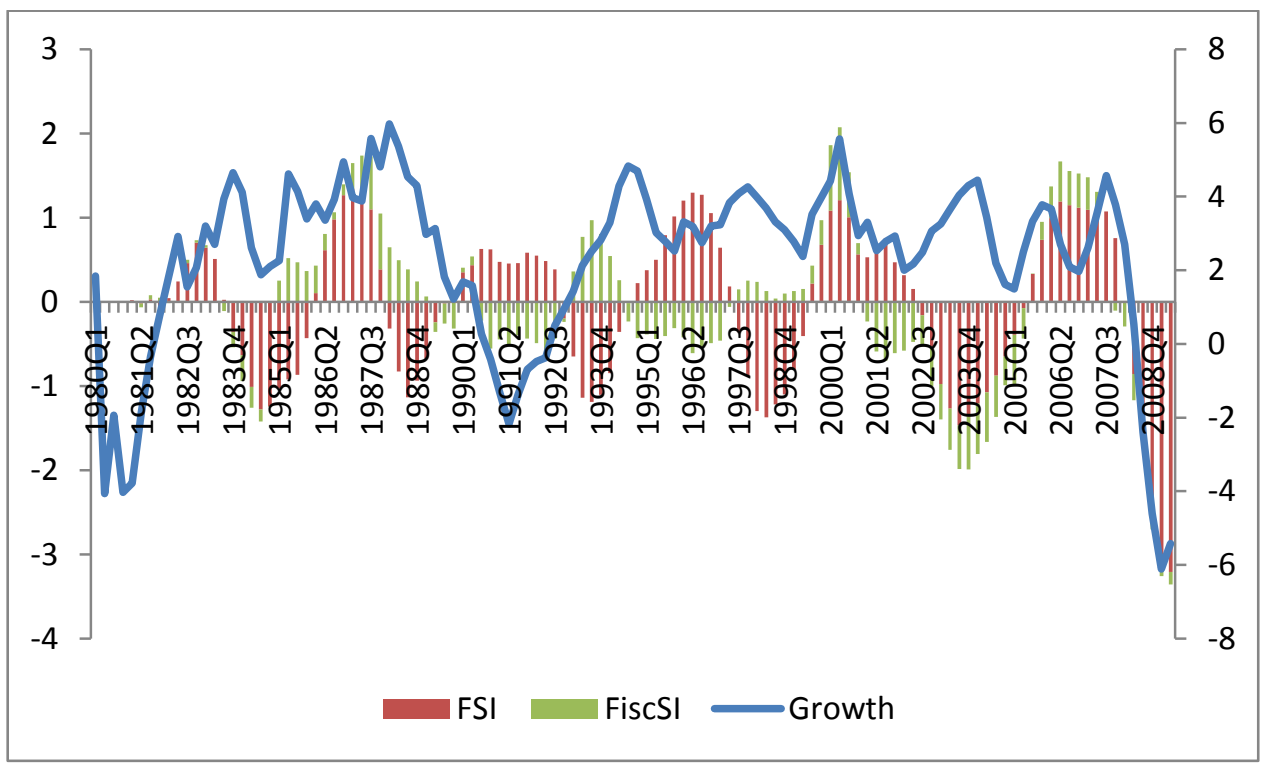




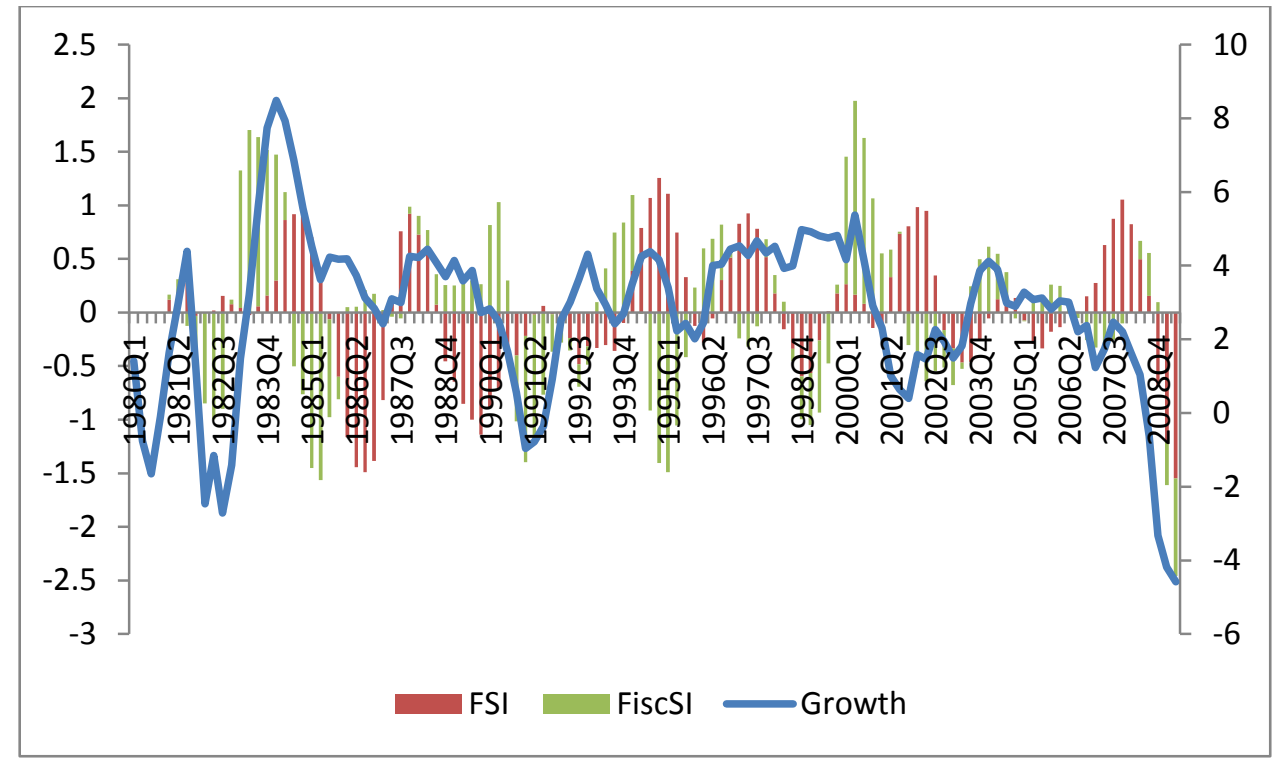

Figure 11: Historical Decompositions of Inflation Rates

Canada

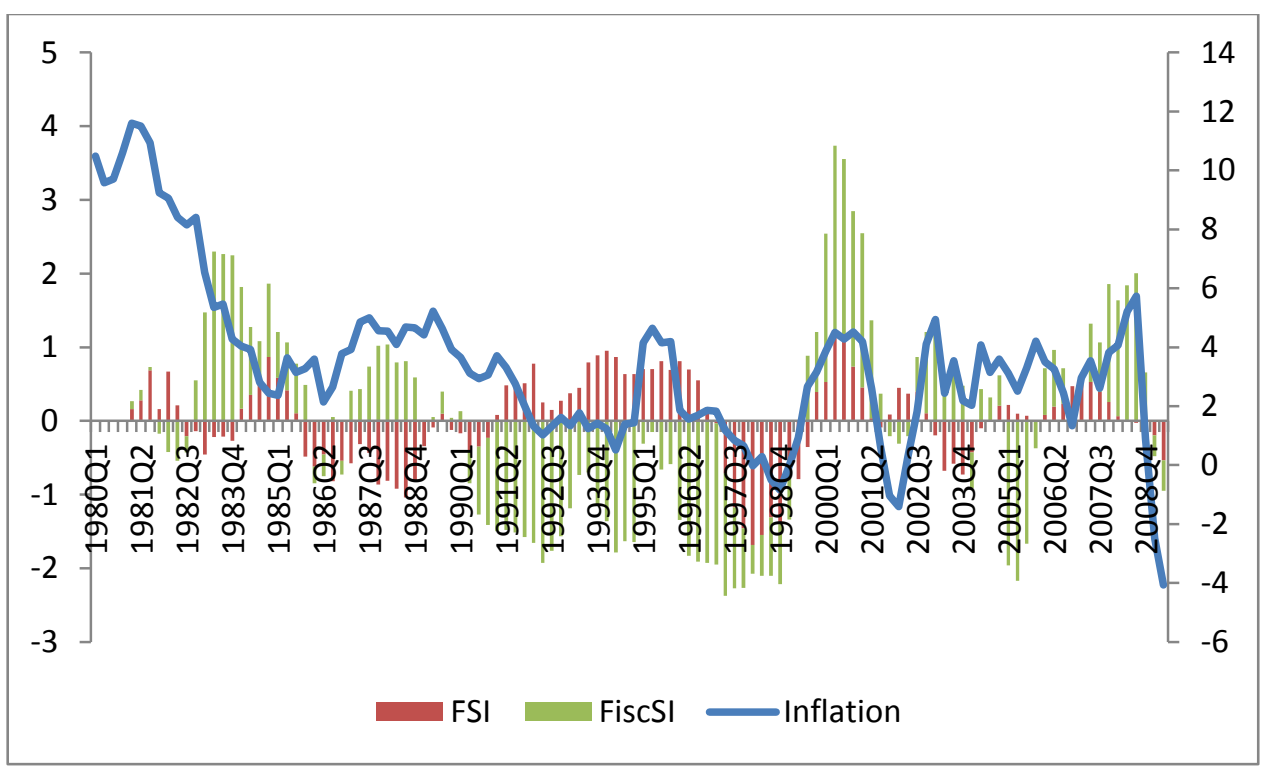


France

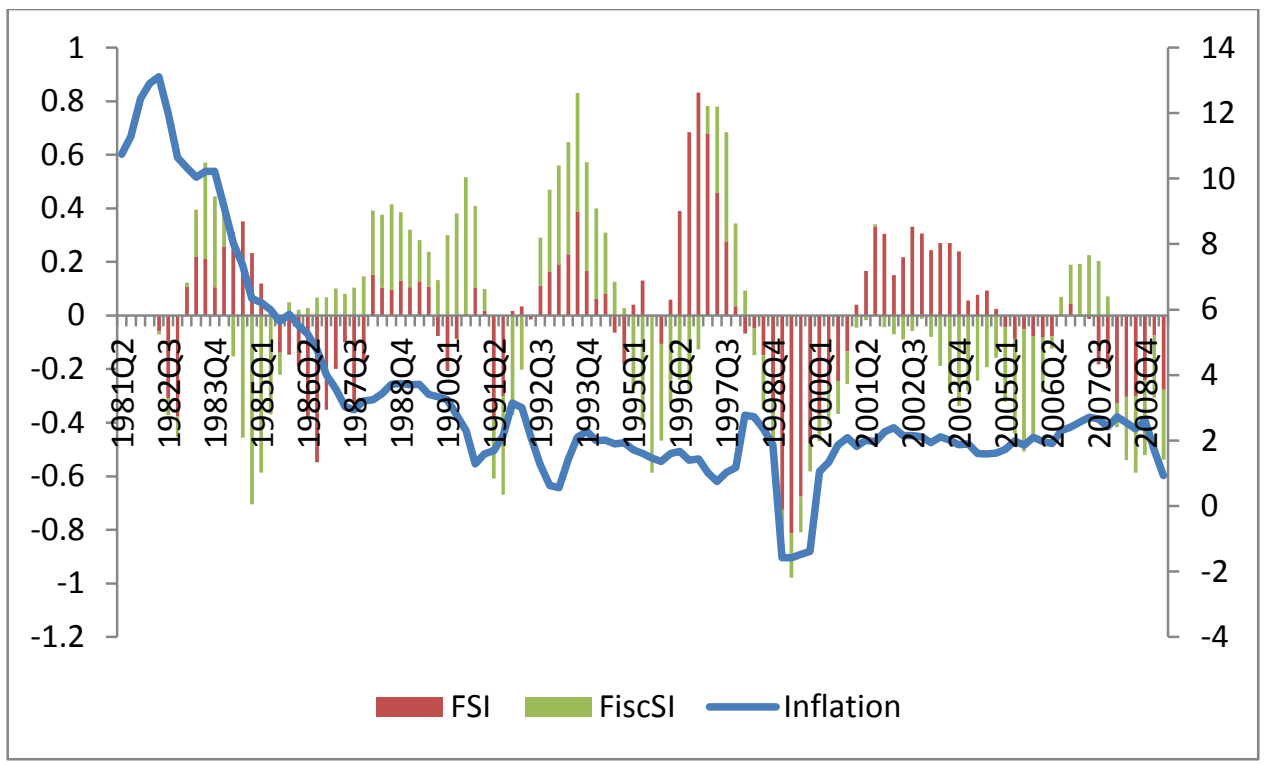

Germany

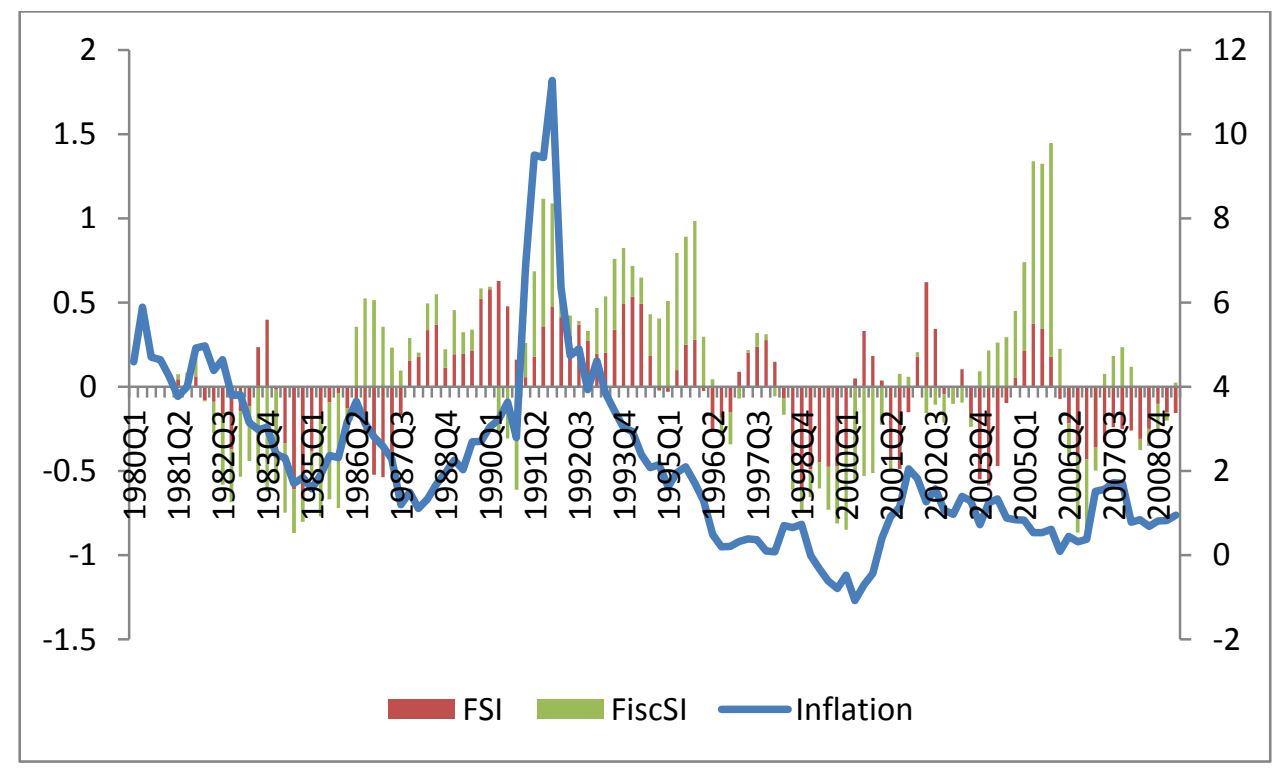


Italy

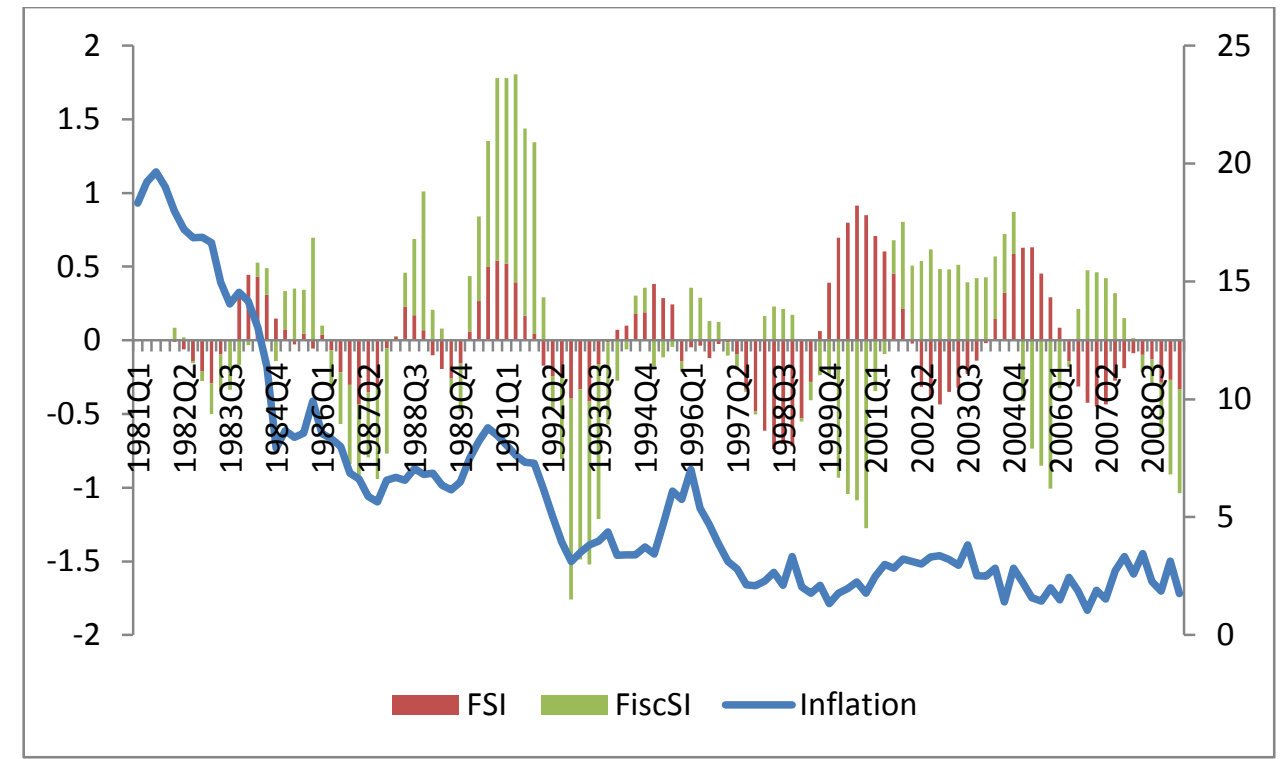

Japan

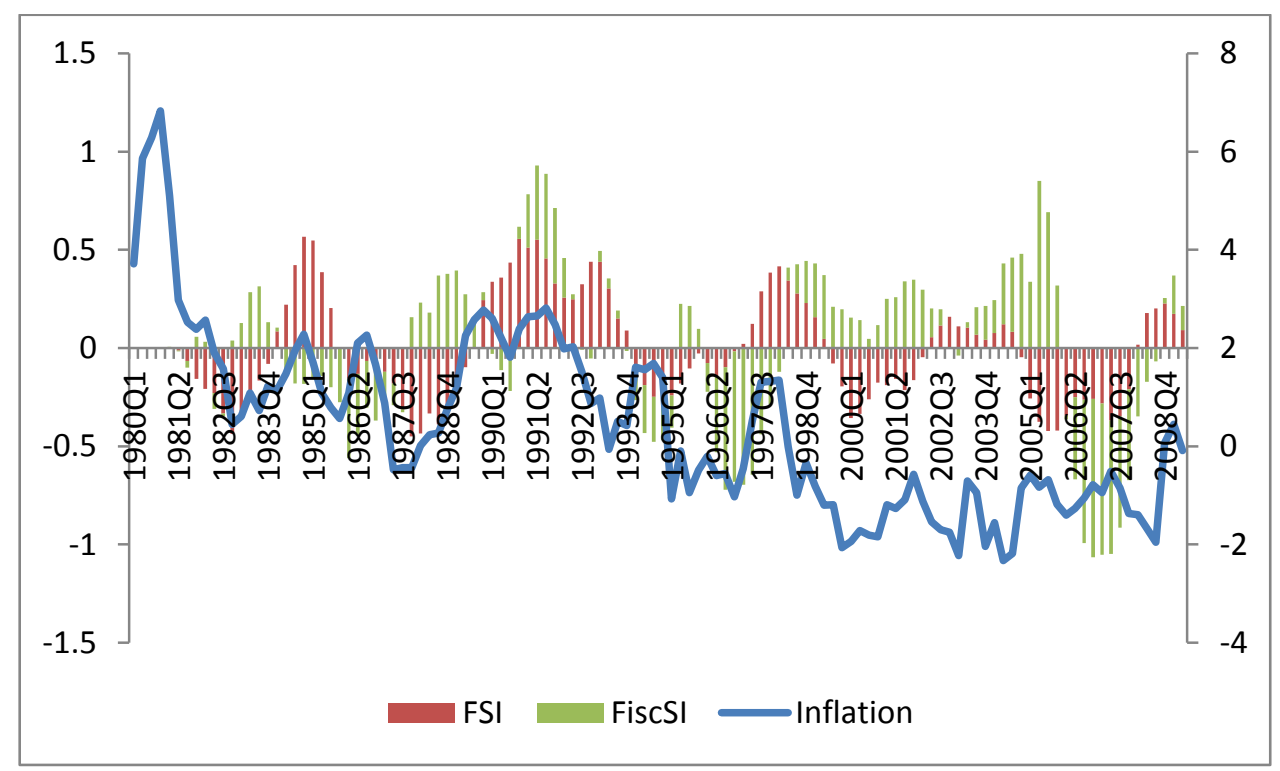


UK

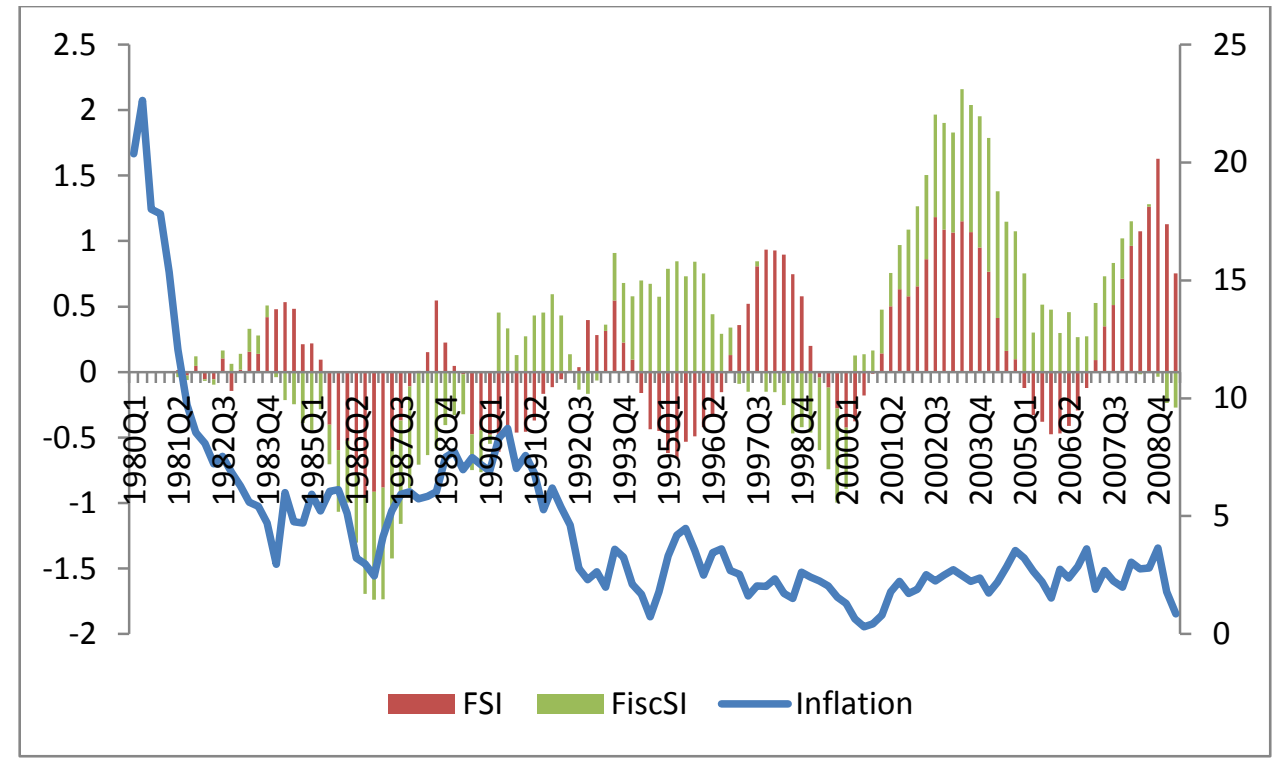

US

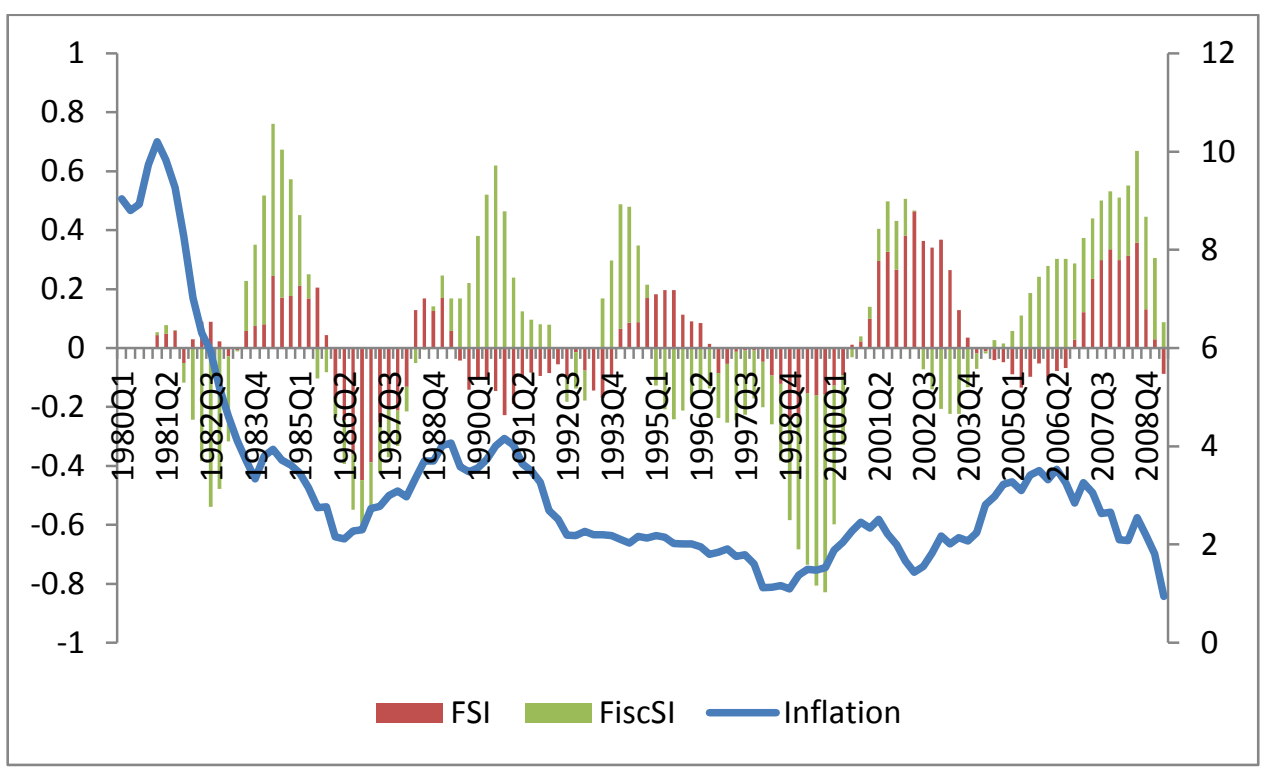


Figure 12: Historical Decompositions of Interest Rates

Canada

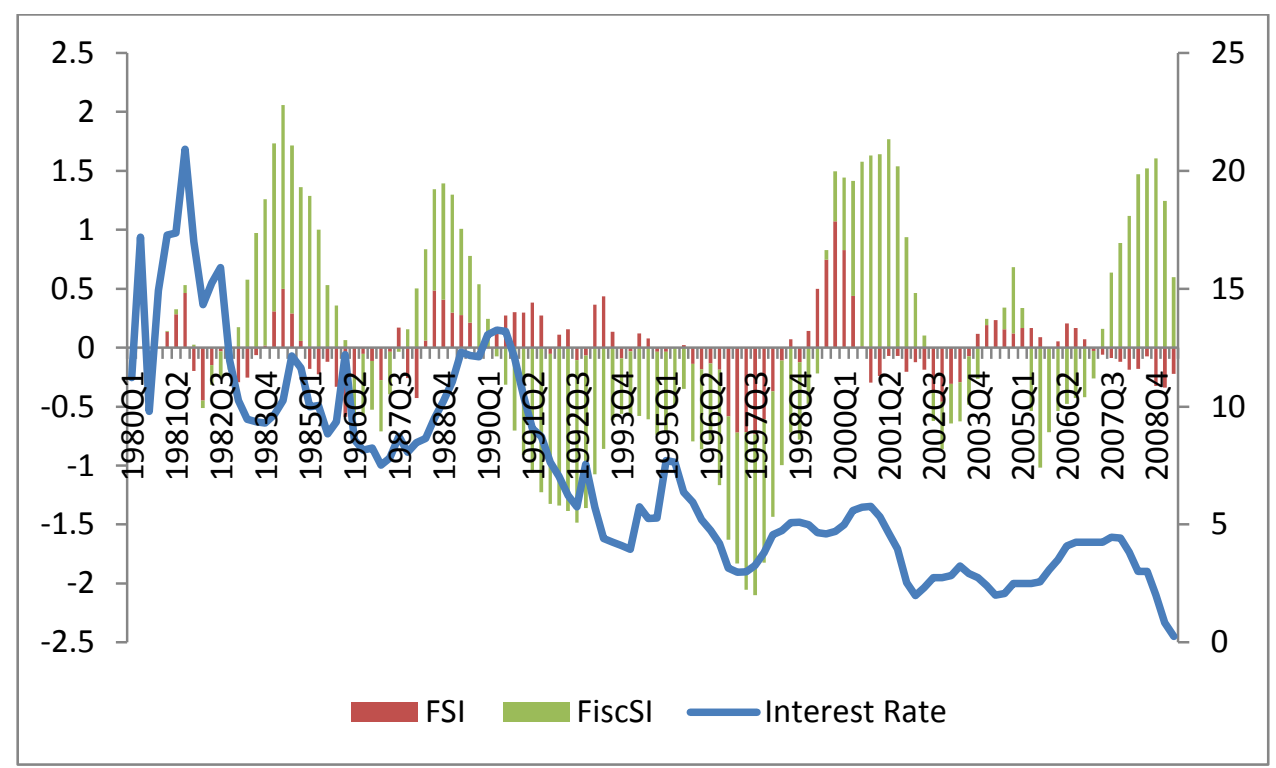

France

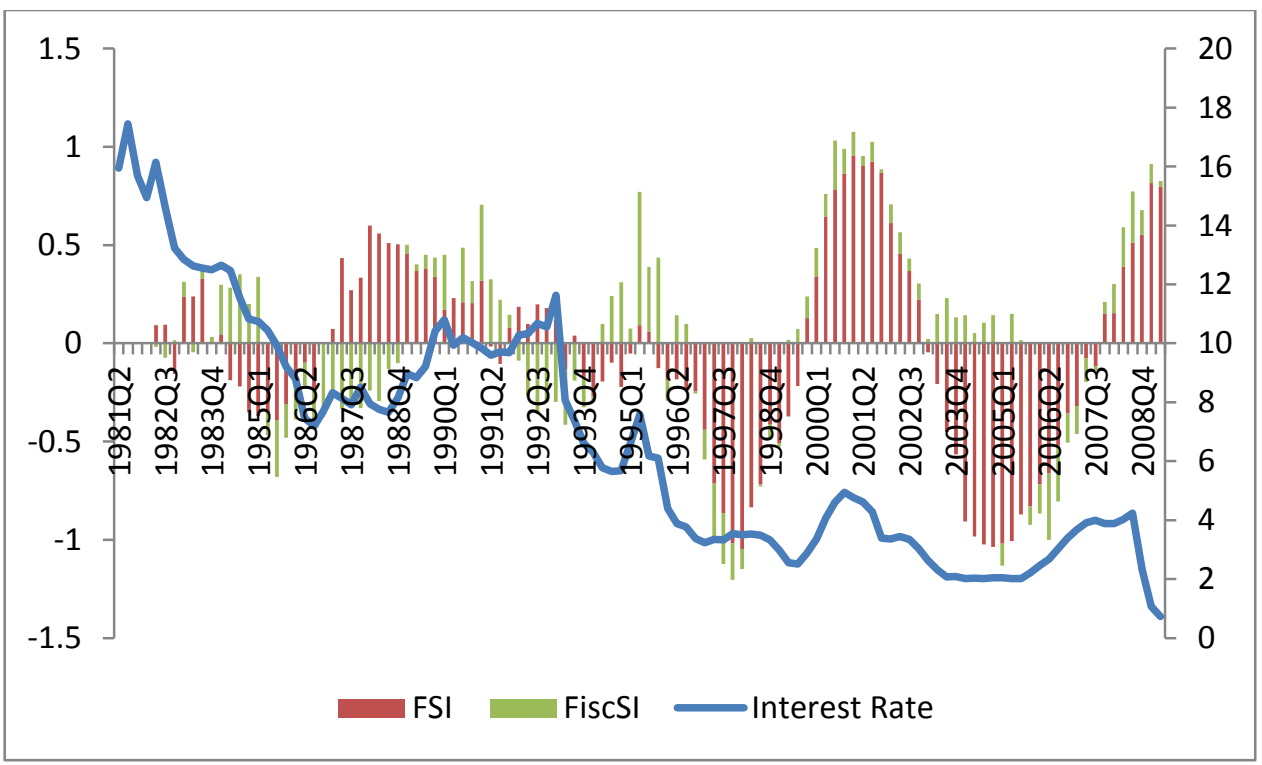


Germany

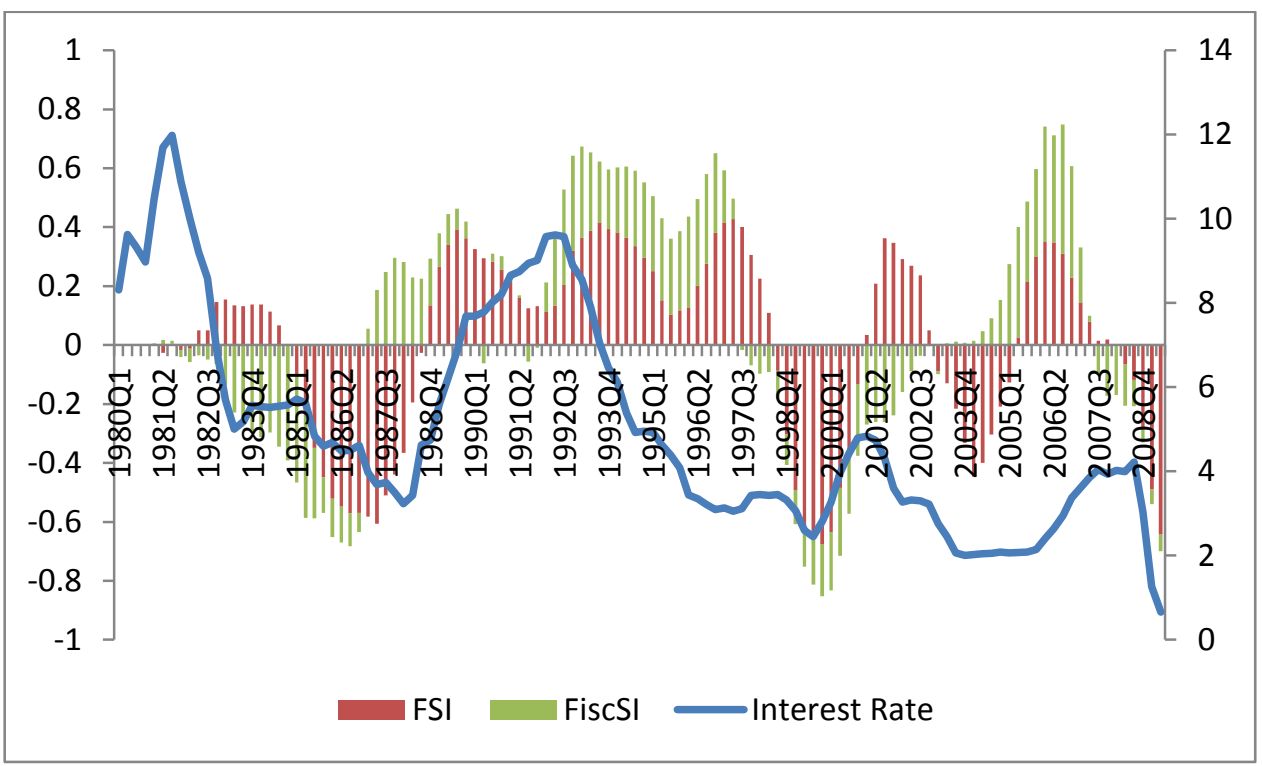

Italy

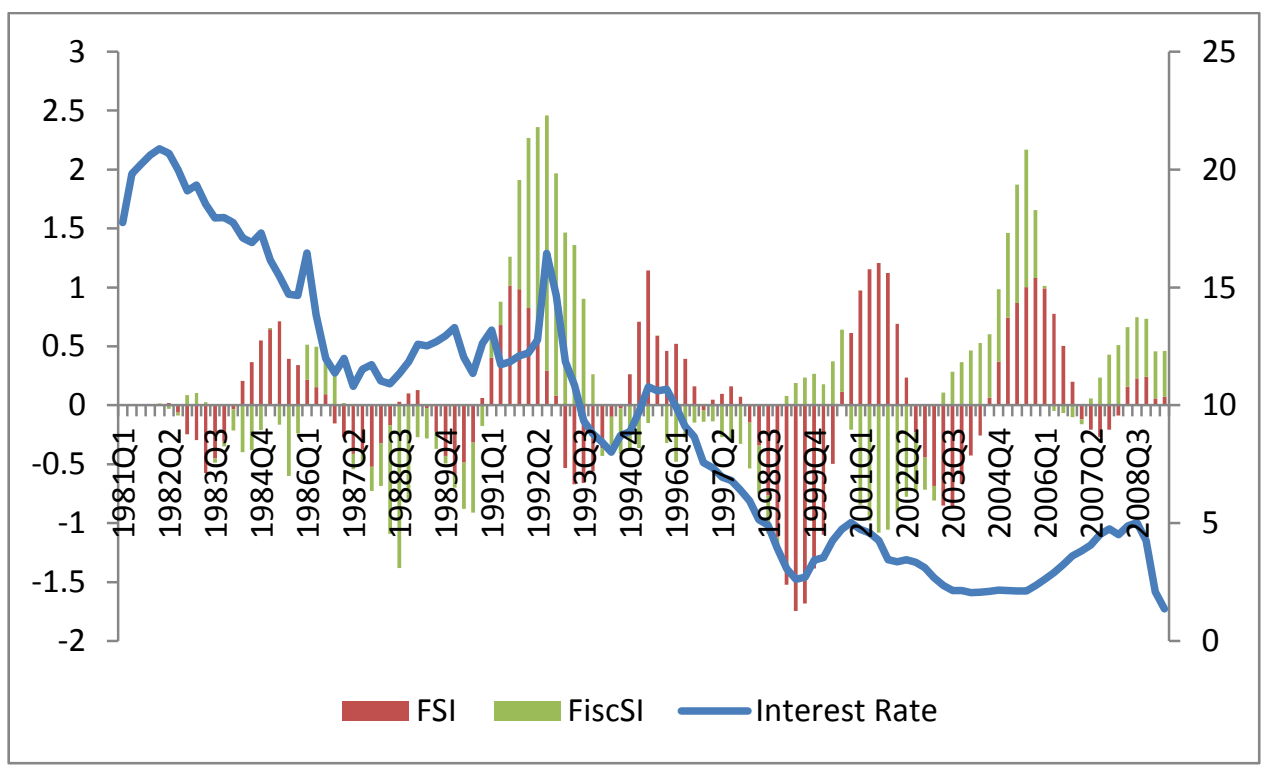


Japan

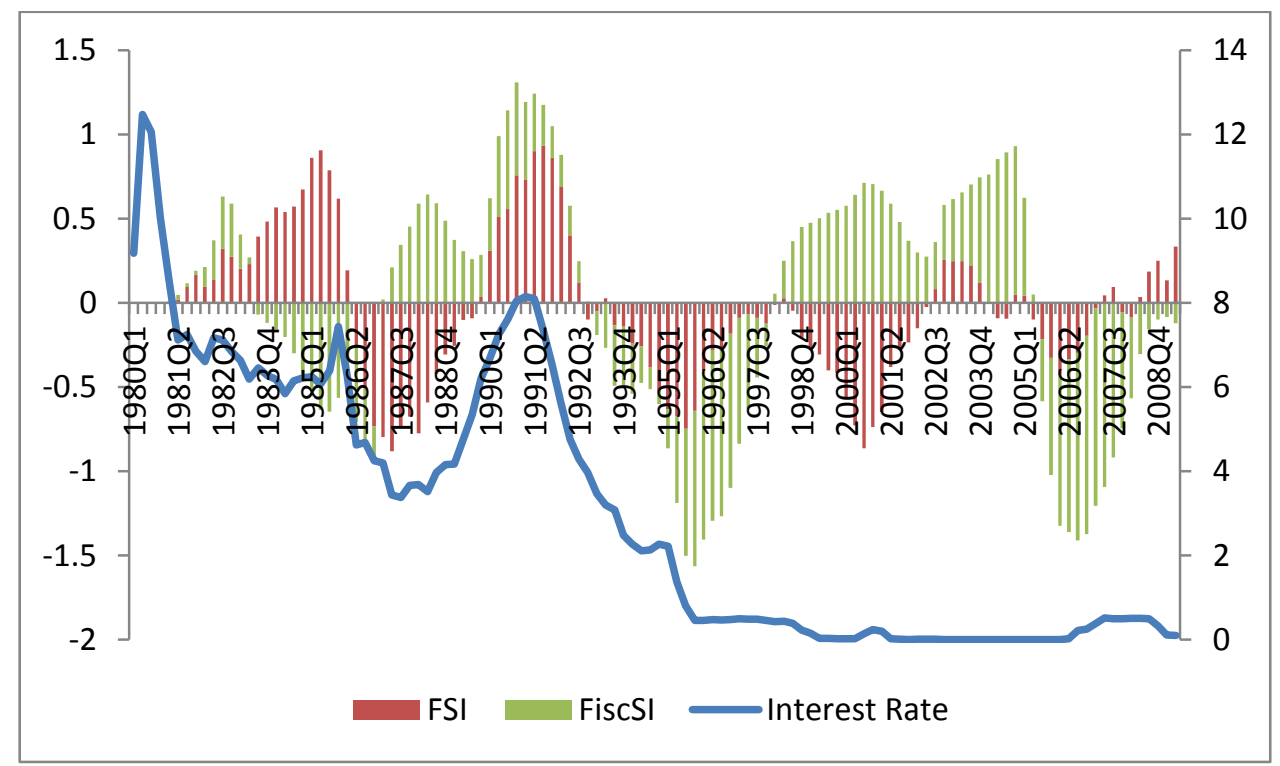

UK

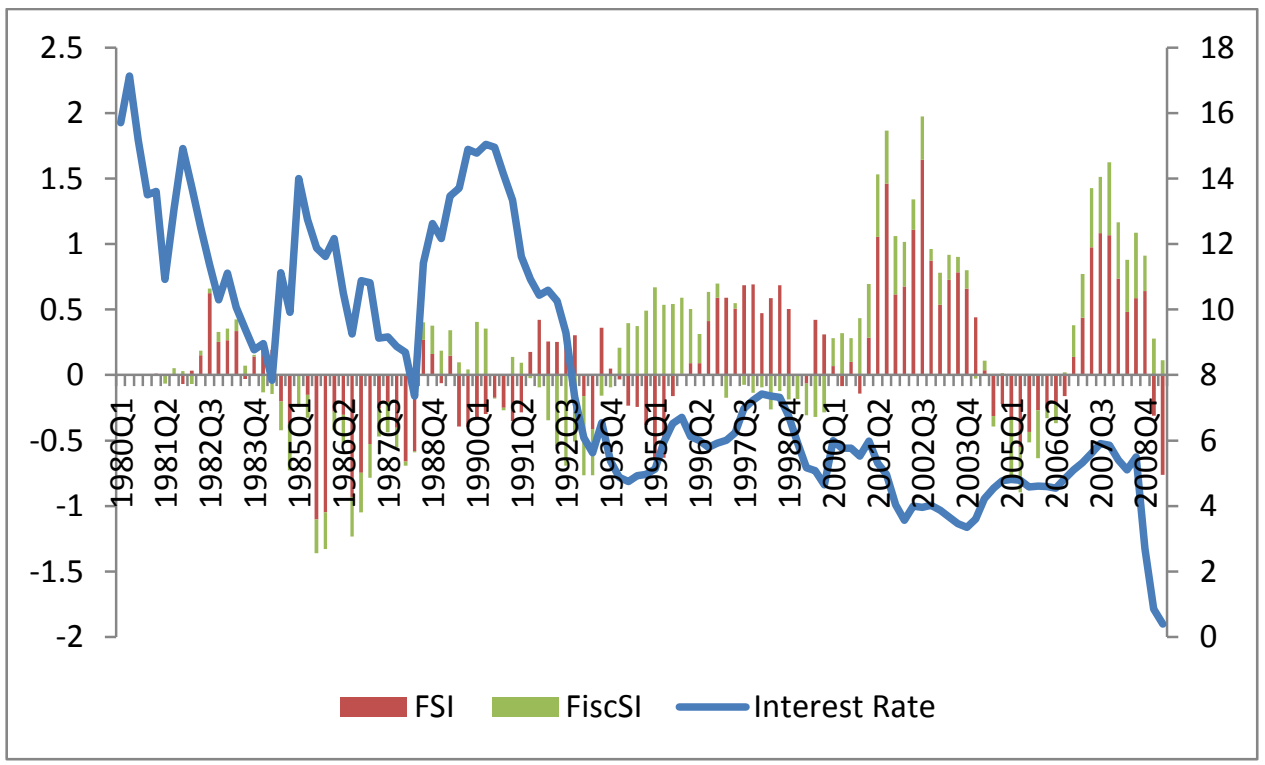


US

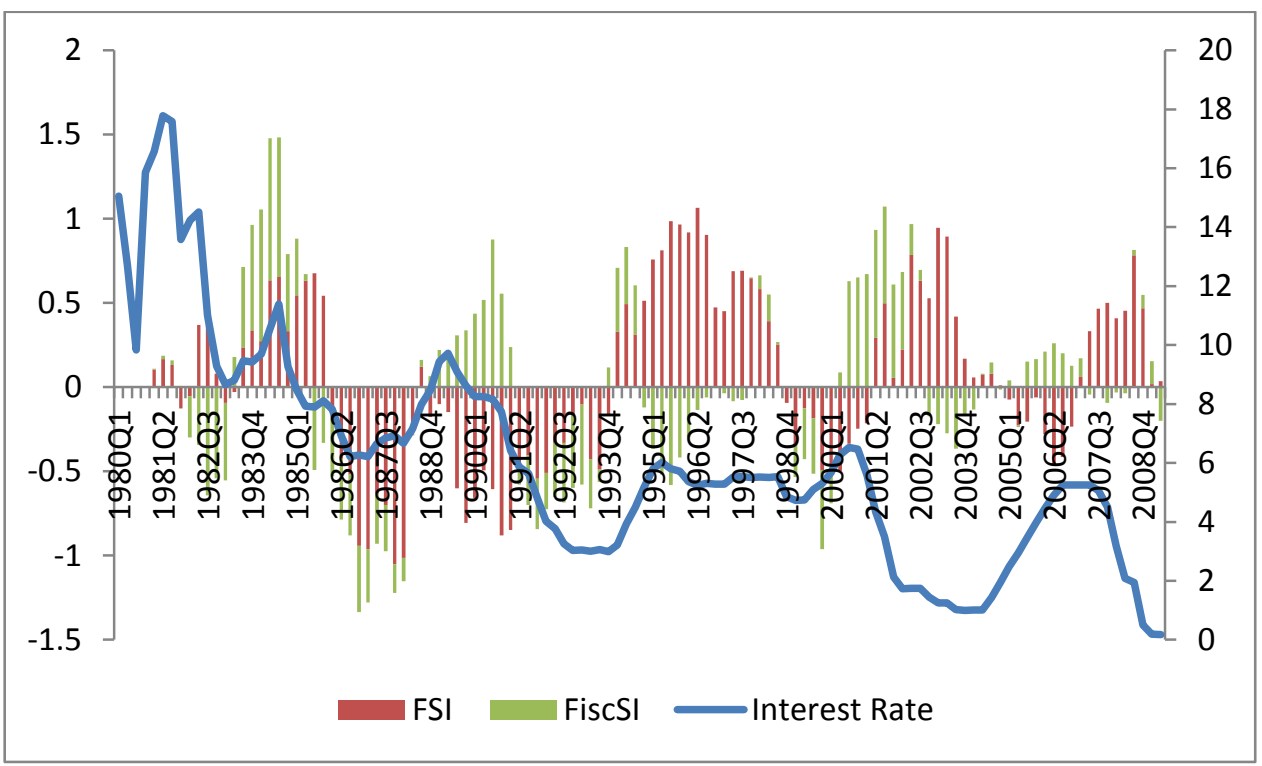


Figure 13: Canada Impulse Responses using pure sign restrictions
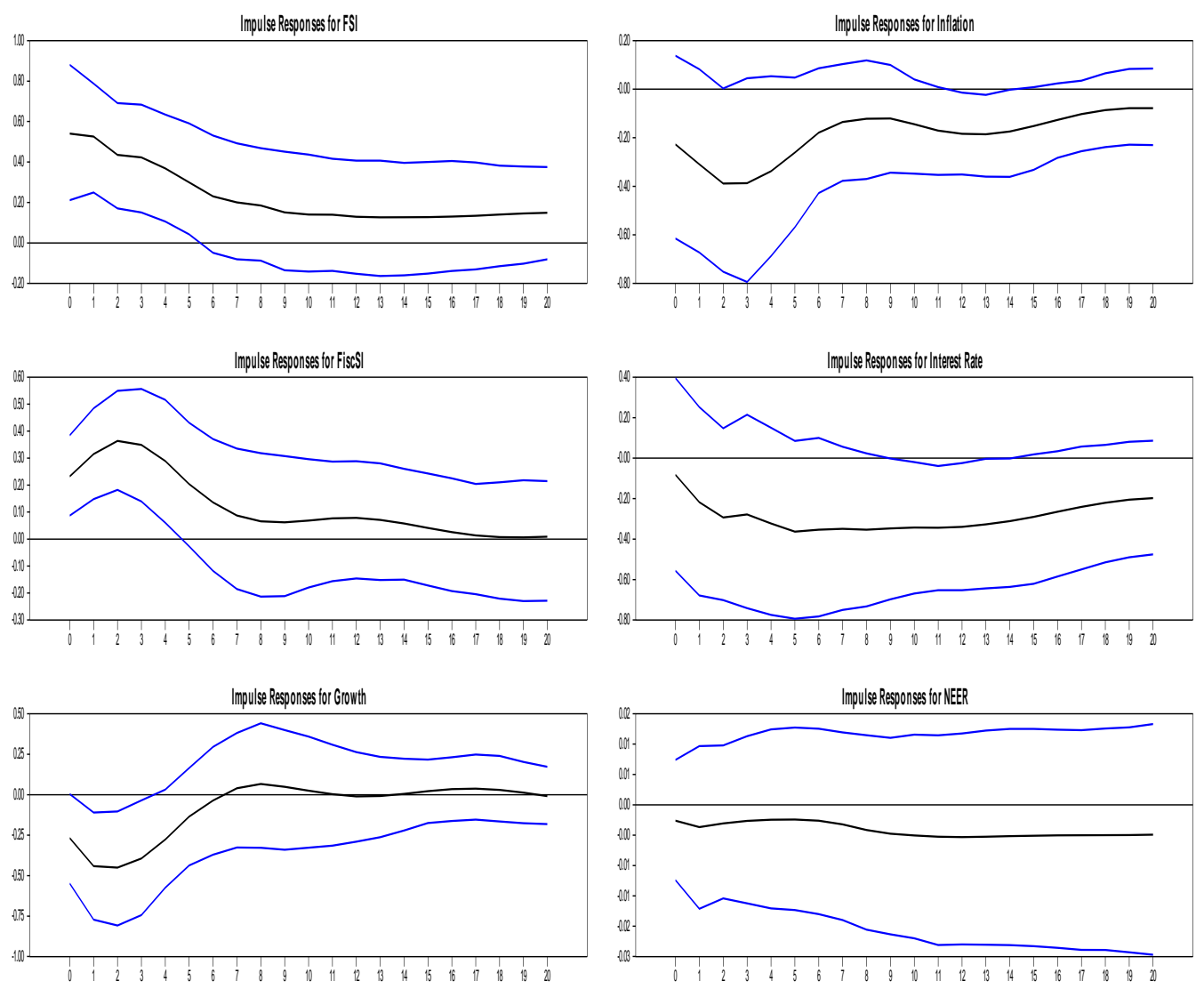
Figure 14: France Impulse Responses using pure sign restrictions
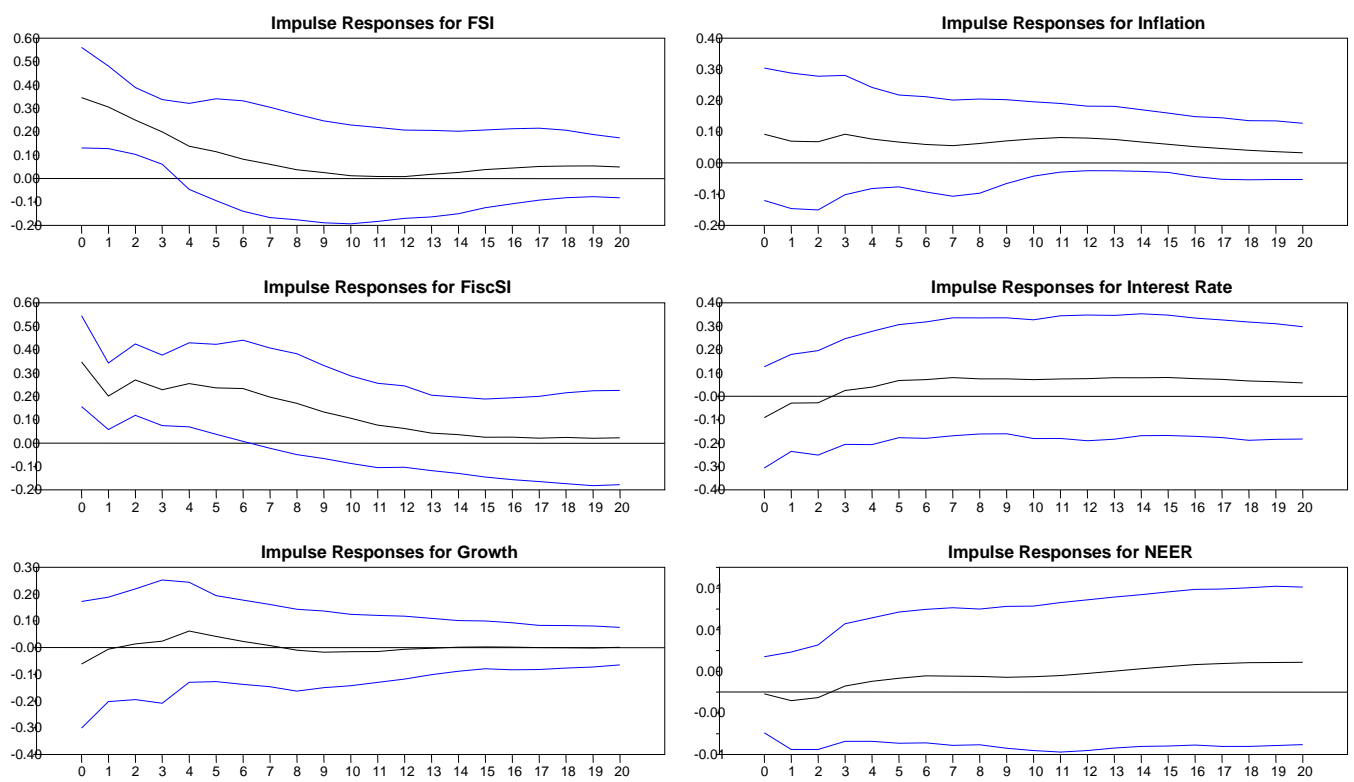
Figure 15: Germany Impulse Responses using pure sign restrictions
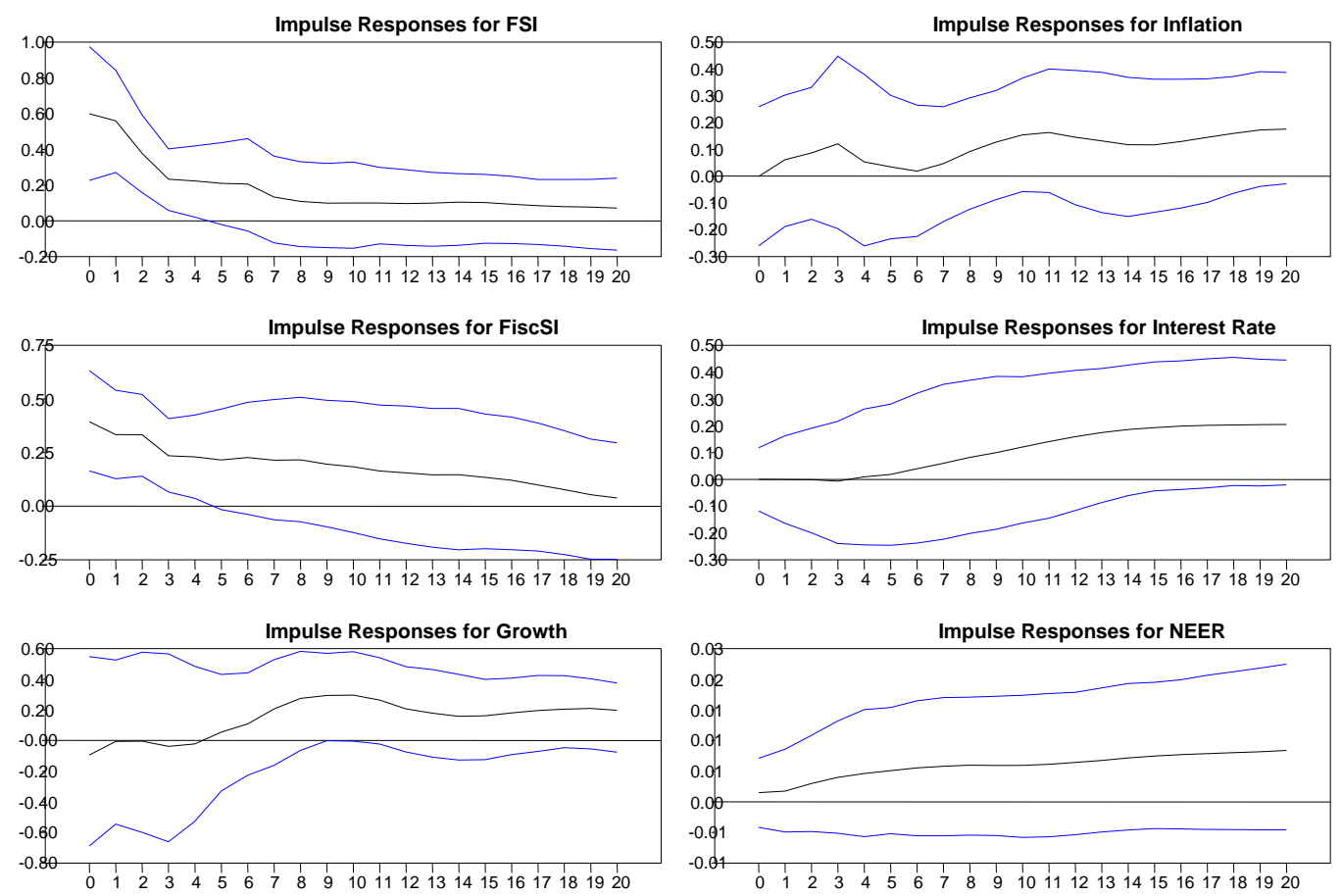
Figure 16: Italy Impulse Responses using pure sign restrictions
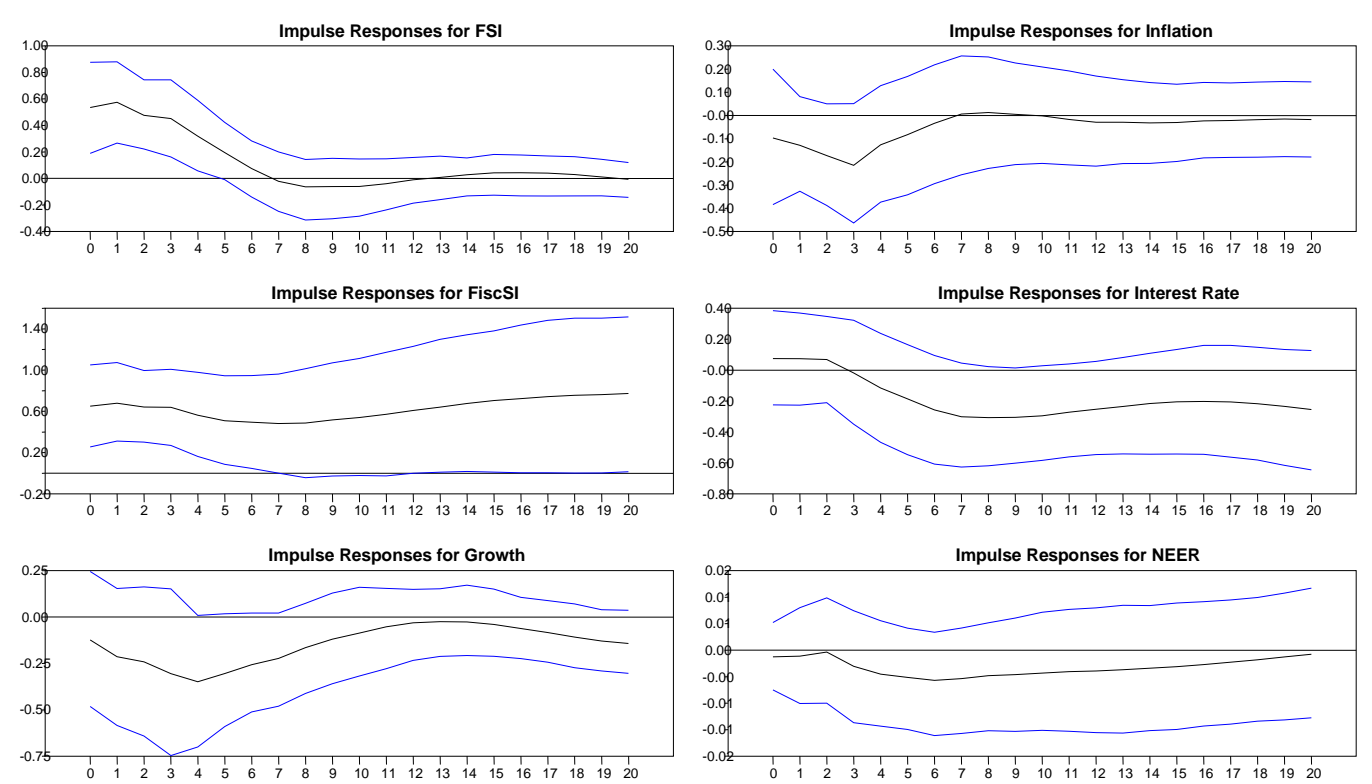
Figure 17: Japan Impulse Responses using pure sign restrictions
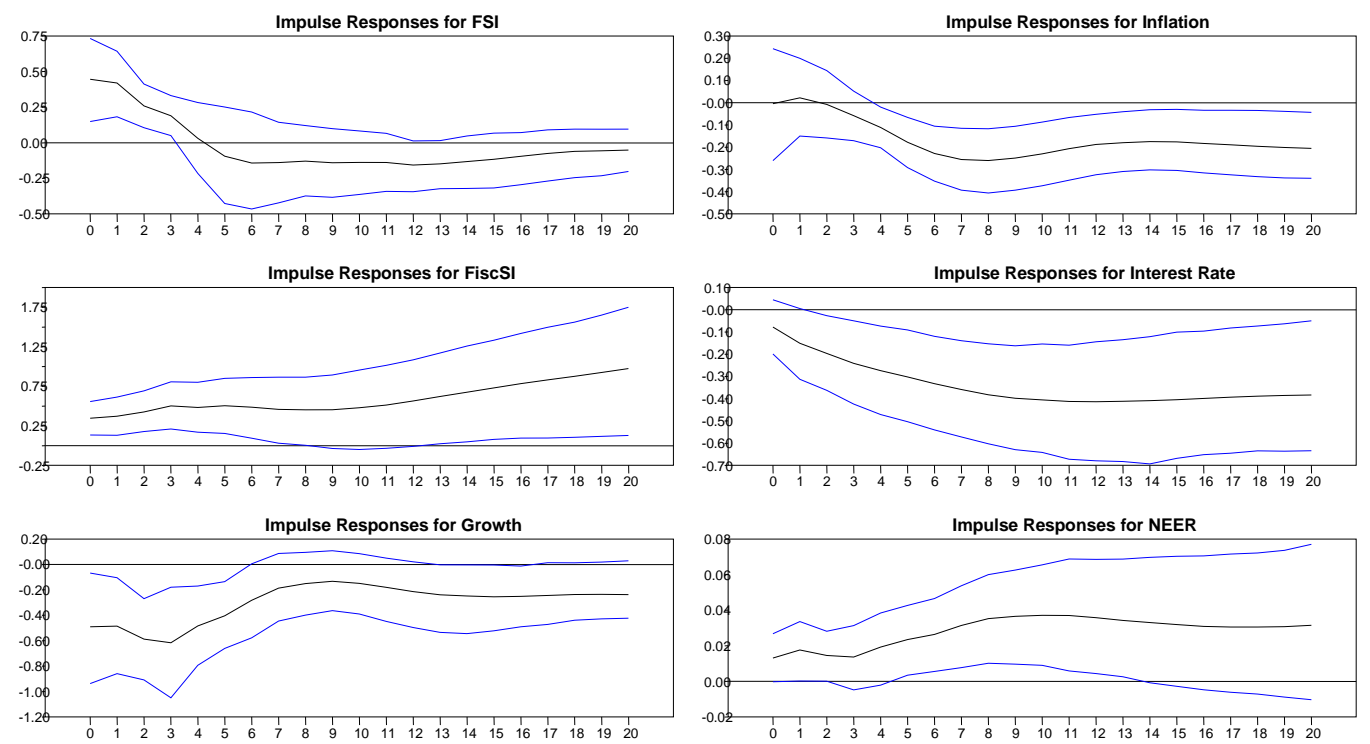
Figure 18: UK Impulse Responses using pure sign restrictions
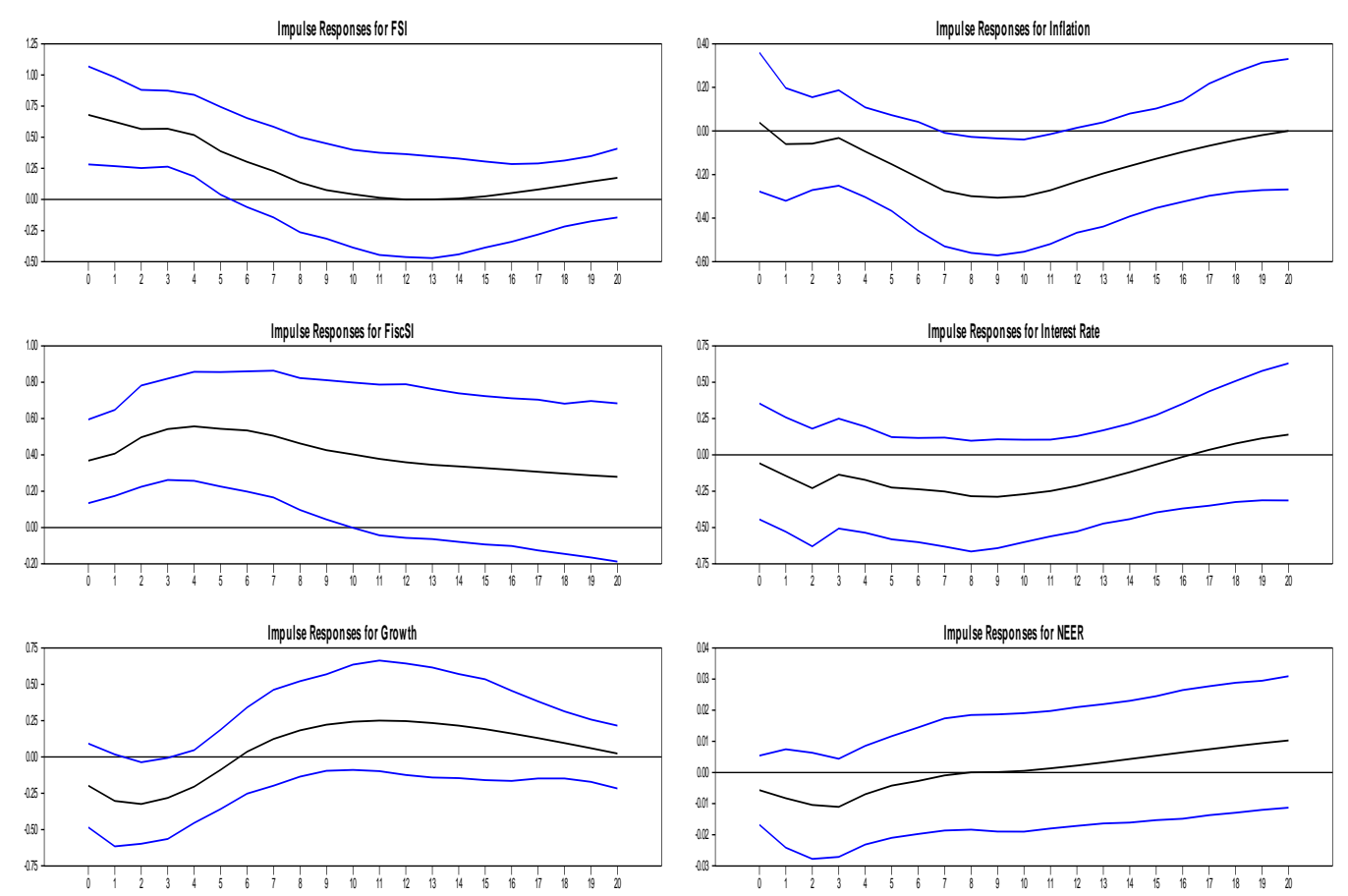
Figure 19: US Impulse Responses using pure sign restrictions
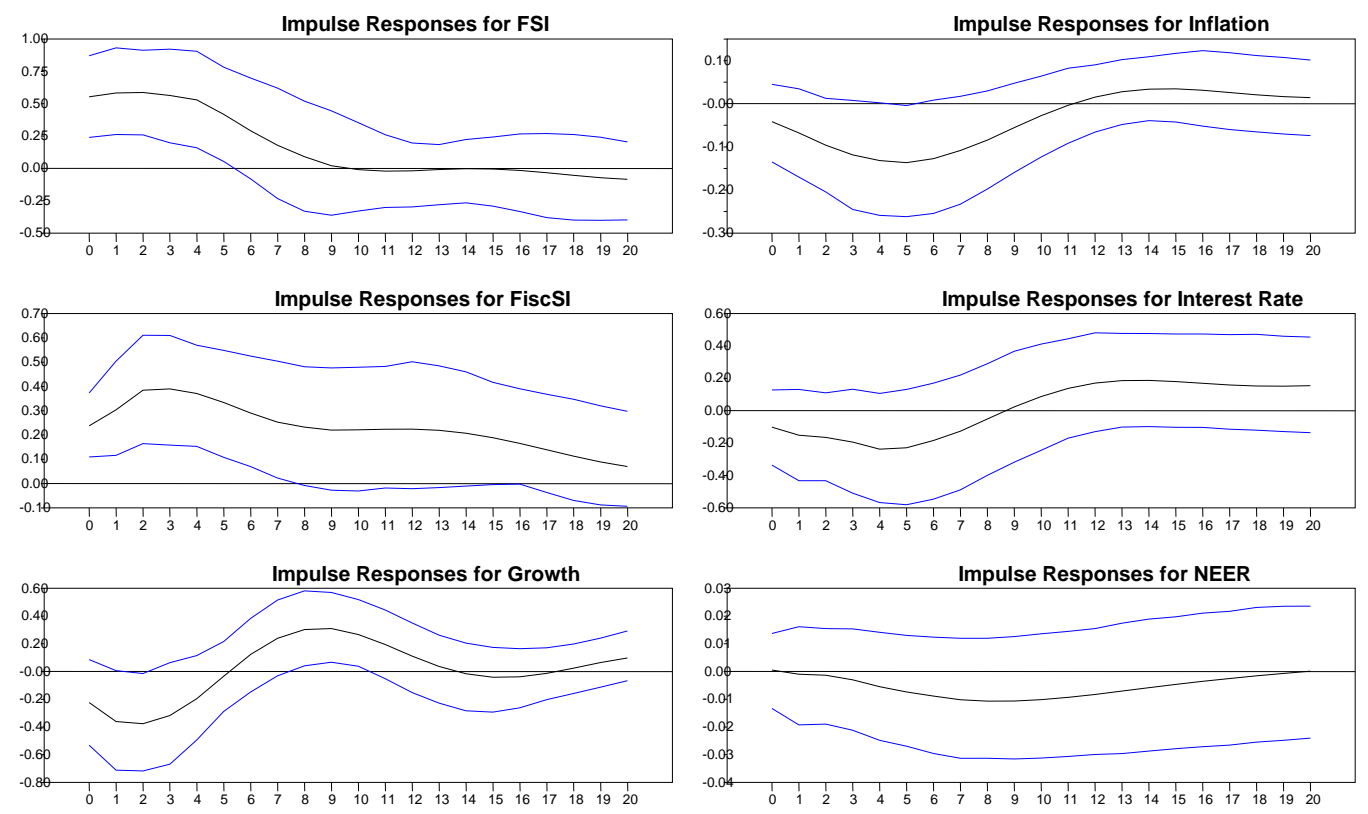
Tables

Table 1: Testing Over-Identifying Restrictions

\begin{tabular}{|c|c|c|c|c|c|c|c|}
\hline & \multicolumn{7}{|c|}{$p$-values } \\
\hline Assumptions: & Canada & France & Germany & Italy & Japan & UK & US \\
\hline 1. $x_{21}=0$ & 0.236 & 0.365 & 0.924 & 0.686 & 0.192 & 0.139 & 0.144 \\
\hline 2. $\mathrm{X}_{31}=0$ & 0.648 & 0.178 & 0.434 & 0.070 & 0.982 & 0.023 & 0.008 \\
\hline 3. $\mathrm{x}_{51}=\mathrm{x}_{52}=0$ & 0.202 & 0.156 & 0.620 & 0.758 & 0.084 & 0.152 & 0.010 \\
\hline 4. $\mathrm{X}_{21}=\mathrm{X}_{31}=\mathrm{X}_{51}=\mathrm{X}_{52}=0$ & 0.315 & 0.235 & 0.855 & 0.338 & 0.153 & 0.041 & 0.008 \\
\hline
\end{tabular}

Note: The entries show $p$-values for the null hypothesis depicted in the first column. 